NBER WORKING PAPER SERIES

\title{
ECONOMIC DATA ENGINEERING
}

Andrew Caplin

Working Paper 29378

http://www.nber.org/papers/w29378

\author{
NATIONAL BUREAU OF ECONOMIC RESEARCH \\ 1050 Massachusetts Avenue \\ Cambridge, MA 02138 \\ October 2021
}

Deep thanks to Daniel Martin, Stefan Bucher, and Soren Leth-Petersen for helping me conceptualize the broad sweep and implement the fine details of this paper, four anonymous referees and the editor for helping me sharpen ideas and focus, as well as Ernst Fehr, Mike Woodford, Markus Reinhard, Danny Goroff, Ruben Garcia-Santos and participants in the SloanNOMIS Program on the Cognitive Foundations of Economic Behavior for supporting the broader push toward interdisciplinary research. The views expressed herein are those of the author and do not necessarily reflect the views of the National Bureau of Economic Research.

NBER working papers are circulated for discussion and comment purposes. They have not been peer-reviewed or been subject to the review by the NBER Board of Directors that accompanies official NBER publications.

(C) 2021 by Andrew Caplin. All rights reserved. Short sections of text, not to exceed two paragraphs, may be quoted without explicit permission provided that full credit, including (C) notice, is given to the source. 
Economic Data Engineering

Andrew Caplin

NBER Working Paper No. 29378

October 2021

JEL No. A12,C0,D01,D15,D80

\begin{abstract}
$\underline{\text { ABSTRACT }}$
Economic data engineering deliberately designs novel forms of data to solve fundamental identification problems associated with economic models of choice. I outline three diverse applications: to the economics of information; to life-cycle employment, earnings, and spending; and to public policy analysis. In all three cases one and the same fundamental identification problem is driving data innovation: that of separately identifying appropriately rich preferences and beliefs. In addition to presenting these conceptually linked examples, I provide a general overview of the engineering process, outline important next steps, and highlight larger opportunities.
\end{abstract}

Andrew Caplin

Department of Economics

New York University

19 W. 4th Street, 6th Floor

New York, NY 10012

and NBER

andrew.caplin@nyu.edu 


\title{
Economic Data Engineering*
}

\author{
Andrew Caplin ${ }^{\dagger}$
}

October 2021

\begin{abstract}
Economic data engineering deliberately designs novel forms of data to solve fundamental identification problems associated with economic models of choice. I outline three diverse applications: to the economics of information; to life-cycle employment, earnings, and spending; and to public policy analysis. In all three cases one and the same fundamental identification problem is driving data innovation: that of separately identifying appropriately rich preferences and beliefs. In addition to presenting these conceptually linked examples, I provide a general overview of the engineering process, outline important next steps, and highlight larger opportunities.
\end{abstract}

JEL Codes: D8, D9, D15

\section{Introduction}

These are exciting times for social scientific research. The many ongoing technological and scientific revolutions are creating unparalleled advances in data availability. We are able to access not only data sets that are massive in scale, but also data sets that are new in form, including search data, order book data, social network data, and even rich biological data. This massive expansion in the volume and form that social scientific data sets take is creating ever richer possibilities for modeling and model estimation, for example allowing individual differences to be taken seriously. At the same time, it is giving rise to intricate conceptual and econometric identification problems (Haavelmo, 1944, Koopmans, 1948, Marschak, 1953, Heckman and Urzua, 2010). Absent strong

\footnotetext{
* Draft for Journal of Economic Literature. Deep thanks to Daniel Martin, Stefan Bucher, and Soren Leth-Petersen for helping me conceptualize the broad sweep and implement the fine details of this paper, four anonymous referees and the editor for helping me sharpen ideas and focus, as well as Ernst Fehr, Mike Woodford, Markus Reinhard, Danny Goroff, Ruben Garcia-Santos and participants in the Sloan-NOMIS Program on the Cognitive Foundations of Economic Behavior for supporting the broader push toward interdisciplinary research.

$\dagger$ Center for Experimental Social Science and Department of Economics, New York University. Email: andrew.caplin@nyu.edu
} 
qualitative and quantitative assumptions, many different models can rationalize patterns observed in the data sets that are flowing in.

Rather than taking advantage of data innovations that are essentially exogenous to modeling, I shine a light on recent research in which new forms of data are developed according to the dictates of economic theory. Economic data engineering deliberately designs novel forms of data precisely to solve fundamental identification problems. One such innovation in the form as opposed to the volume of data involves design of survey instruments to resolve identification problems in dynamic models of behavior. A second such innovation is state dependent stochastic choice data which measures choices conditional on facts that may have escaped the decision maker's attention. Both of these are taken up in detail below. In these and other such cases, the starting point is not a new flow of data liberated by advances in technology, but rather a key identification problem. Economic data engineering is a highly structured process in which economic theory dictates innovations in the form that economic data should take.

The goal of this paper is to convey recent advances in economic data engineering and to highlight its larger potential. Its methods are quite distinct from the normal science process of gathering ever richer data to estimate ever richer models. To make this point tangible, I outline three different lines of research in which economic data engineering is playing an increasingly pivotal role. The areas of research are diverse, relating respectively to the economics of information, life-cycle employment, earnings, and spending, and finally to public policy analysis. While the research challenges are manifold, there are common threads. In all three cases one and the same fundamental identification problem is driving data innovation: that of separately identifying appropriately rich preferences and beliefs. In addition to presenting these conceptually linked examples, I provide a general overview of the engineering process, outline important next steps, and highlight larger opportunities.

The first area of research I cover in depth is information-theoretic data engineering. This develops theory-based methods to identify and understand mistaken decisions. This links two vibrant branches of economic research: study of behavioral mistakes (e.g. Chetty, Looney, and Kroft, 2009, Bhargava, Loewenstein, and Sydnor, 2017) and modeling of attentional constraints (Sims, 1998, Matějka and McKay, 2015, Caplin and Dean, 2015, Caplin et al., 2020, Mackowiak, Matějka, and Wiederholt, 2021). To join these literatures requires first separating utilities and beliefs in behavioral data. I outline a recent literature that uses state dependent stochastic choice data (SDSC) to this end. SDSC records the impact on choice of variation in the underlying state of the world about which the decision maker may be uncertain. Properly processed, such data allows the Blackwell model of experimentation and choice as well as rational inattention theory to be tested. Linear inequalities identify precisely what an econometrician can infer about utility, beliefs, and costs of learning from such data. The result is a novel hybrid of production and consumption theory. What attention produces is better information with which to improve the quality of choices. 
Data engineering sets ambitious targets for measurement, and characterization of mistakes in SDSC is rapidly becoming more prevalent. I outline case studies ranging from the recreational (umpiring baseball) to matters of life and liberty (medical and judicial decisions). I also outline research on attentional discrimination (Bertrand and Mullainathan, 2004, Bartoš et al., 2016), and on feedback effects between economic deprivation, attentional resources, and income (Mani et al., 2013). I outline important next steps in modeling related to learning and to awareness, as well as applications to machine learning. These last two applications reveal how the model-centric approach of economic data engineering opens new areas of applied research.

In the case of life-cycle data engineering, the key innovations involve survey instruments. Following the pioneering work of Manski, 1990, and Dominitz and Manski, 1996, surveys of conditional and unconditional probabilistic beliefs are becoming accepted as part of normal science. In combination with stated preference questions, they are being applied to model such important decisions as educational choice (Arcidiacono et al., 2014, Wiswall and Zafar, 2018, 2021). I also outline more highly structured strategic survey questions that have been applied to such issues as wealth holding and work choices in later life (De Nardi, French, and Jones, 2009, 2010, 2016, and Ameriks et al., 2015, 2020). I stress the general engineering challenge of designing model-based questions that can be intuitively understood by the average respondent.

In section 5 I look forward to rapidly developing life-cycle data engineering in relation to lifetime income (Guvenen et al., 2015, 2021) and to the impact of quits and layoff on these patterns (Menzio, Telyukova, and Visschers, 2016). I illustrate the value of survey-based expectations measurement in understanding search behaviors and loss of income associated with periods out of the labor force (Mueller, Spinnewijn, and Topa, 2021). The ideal is to gather panel data on life-cycle income expectations and realizations in an architecture that contains not only rich administrative data going forward but also great historical detail. This is now feasible in the Danish population registries (Eppers et al. 2020, Andersen and Leth-Petersen, 2021). I introduce the recently initiated Copenhagen Life Panel which uses this architecture to characterize income expectations and subjective risks associated with job transitions. Important next steps include better modeling and measuring the development of income-generating skills over the life-cycle.

The final area I survey involves policy-based data engineering. A key observation in the recent applied literature is the need to properly communicate decision-relevant information. It is now understood that communicating policy effectively is part and parcel of the policy itself. The goal of policy-based data engineering is to understand the channels through which information treatments designed for purposes of communication operate, thereby to guide their design in welfare-enhancing directions. I outline field studies showing important policies to be poorly understood absent informational interventions (Currie, 2008, Chetty and Saez, 2013), as well as survey-based information treatments that measure impacts of communication on beliefs and behavior (Haaland, Roth, and Wolfhardt, 2020). I illustrate integration of policy-based data engineering 
into applied research focusing on communicating future changes in social security policy, and on developing methods of communication to reduce the harmful financial consequences of late-in-life cognitive decline. I also outline ongoing research adapting methods of information-theoretic data engineering to welfare rank information treatments (Caplin and Martin, 2021).

Sections 2 and 3 cover information-theoretic data engineering, sections 4 and 5 life-cycle data engineering, and section 6 policy-based data engineering. Section 7 presents concludes a general perspective on the research process and the larger opportunities it opens.

\section{Information-Theoretic Data Engineering}

Information-theoretic data engineering develops theory-based methods of measurement to identify sources of mistaken decisions. This links one of the most vibrant branches of applied economics with one of the most vibrant branches of theoretical economics. With regard to application, decision making mistakes are ubiquitous, be it failure to internalize sales taxes (Chetty, Looney, and Kroft, 2009 et al., Taubinsky and Rees-Jones, 2018, Morrison and Taubinsky, 2019), failure to claim available benefits (Currie, 2008, Bhargava and Manoli, 2015), failure to take advantage of school scholarships on offer (Hastings and Weinstein, 2008, Hoxby and Turner, 2015), choice of dominated insurance contracts (Bhargava, Loewenstein, and Sydnor, 2017, 2017, Handel and Kolstad, 2015, Abaluck et al., 2018, Kling et al., 2012), or choice of inefficient farming practices (Hanna, Mullainathan, and Schwartzstein, 2014). With regard to theory, models of attentional constraints and bounds on rationality are blossoming, as witness rational inattention theory (Sims, 1998, 2003, Matějka and McKay, Caplin and Dean, 2015, Caplin et al., 2020, Caplin, Dean, and Leahy, 2021, Mackowiak, Matejka, and Wiederholt, 2021), efficient coding theory (Khaw, Li, and Woodford, 2017, Glimcher, 2014, Louie, Khaw, and Glimcher, 2013, Woodford, 2020), sparsity theory (Gabaix, 2014), and salience theory (Bordalo, Gennaioli, and Shleifer, 2012).

The key challenge of joining model with measurement is obvious, first order, and deeply rooted in the history of economic thought. When choices involve navigating trade-offs, how can one separate out utilities and beliefs and thereby identify mistakes? To what extent does choice of an inexpensive car with low resale value over a more expensive one with higher resale value reflect a wellinformed trade-off, and to what extent an ill-informed mistake?

In section 2.1 I formalize the underlying challenge and provide methodological backdrop to the information-theoretic engineering process. Section 2.2 introduces the key data innovation: state dependent stochastic choice data (SDSC), which records the impact on choice of changes in the underlying facts and links it with the basic expected utility model of information constrained choice. In section 2.3 I outline how SDSC helps in separately identifying beliefs, utilities, and therefore mistakes. In section 2.4 I show how to further engineer SDSC to test rational inattention theory, and where appropriate to infer costs of learn- 
ing. I note the powerful analogies with production and consumption theory. Special cost functions and their impact on the form of mistakes are introduced in section 2.5 .

\subsection{The Fundamental Identification Problem}

To make the engineering challenge precise, I specify the standard theory of choice under uncertainty, which, following the pioneering work of Hayek, 1937, 1945, Von Neumann and Morgenstern, 1944, Blackwell, 1953, Savage, 1954, and Stigler, 1960, is the dominant model of individual behavior. There are uncertain payoff-relevant states of the world $\omega$ and prior beliefs $\mu(\omega)$ over them. There are available actions $a \in A$ whose reward depends on the true state. The utilityrelevant consequences are a deterministic function of the action and the state, $z(a, \omega)$, with $u(z)$ the expected utility for consequence $z$.

The decision maker investigates the state in some manner and then chooses an action. What is known by the decision maker at point of decision is described by a subjective experiment in the sense of Blackwell, 1953. Technically, the decision maker receives stochastic signals about the state which lead them to update. One can simplify the description of such a Blackwell experiment as involving a Bayes' consistent distribution of posteriors that specifies probabilities $Q(\gamma)>0$ of possible subjective posteriors $\gamma$ (Kamenica and Gentzkow, 2011, Benoit and Dubra, 2011). The Bayesian constraint corresponds to these averaging back to the prior,

$$
\sum_{\gamma} \gamma Q(\gamma)=\mu .
$$

Mistakes arises when an action is chosen over an alternative that, in reality, would have yielded higher utility.

The information-theoretic engineering challenge is to find a data set that operationalizes key constructs in this standard model of learning and choice. The guiding light is Samuelson's profound insight into the operational limits of standard choice theory. Despite the advance in which subjectively intuitive notions such as diminishing marginal utility theory were replaced with indifference relations, he questioned the theory's operational status (see Dixit, 2002, for methodological background).

".. just as we do not claim to know by introspection the behaviour of utility, many will argue we cannot know the behaviour of ratios of marginal utilities or of indifference directions." (Samuelson, 1938, p.61.)

The deep power of this operational stance is too little appreciated. One can paraphrase precisely in relation to the standard model of learning and choice:

Just as we do not claim to know by introspection the signals that a subjective experiment produces, many will argue we cannot know the distribution of 
posteriors to which it gives rise.

In formal terms, even if the econometrician observes actions, states, and prizes, both the decision maker's utility function and the posteriors about the state of the world are subjective (this was highlighted by Machlup, 1993, in differentiating between the contents of a transmitted message and comprehension of it). The path forward that data engineering suggests is to follow Samuelson's lead and to conceptualize an ideal data set that allows beliefs and utilities to be separately identified. In fact this is precisely what Block and Marschak, 1959, proposed when introducing stochastic choice data into economic analysis. While modeling randomness in utility, they were intimately aware of psychological models dating back to Thurstone, 1927, 1931, and Luce, 1956, 1958, in which stochasticity in choice derives from the imperfect ability to discriminate between "percepts". For that reason they were powerfully struck by the identification problem as between beliefs and utility, or "information and desirability" as they phrased it (Block and Marschak, 1959 p. 1.6).

The centrality of this belief/utility identification problem is set in stark relief when one considers decisions made with incomplete information. The classical theory that Samuelson introduced specifies that choice from any subset of a grand choice set is guided by maximization of a complete and transitive preference relation. The data set in which Samuelson proposed testing this theory involves observing choice from all subsets of the grand choice set. The theory implies that these chosen elements comprise all maximal elements according to the fixed preference ordering. If this is all there is to it, then the only way to interpret an incorrect answer on a math test is as reflecting a preference for getting the answer wrong. To double down on this example, a student getting all answers wrong would satisfy the strong axiom of revealed preference and we would happily see our model as perfectly fitting the application.

The deep problem is precisely that raised by Block and Marschak. Incorrect answers reflect the student's lack of knowledge: in model terms, they are unable to correctly identify the state of the world. In its classical form, revealed preference theory assumes this away with the identifying assumption that information is perfect. If one believes information always to be imperfect, as I do, the identification problem as between beliefs and preferences must take center stage. Developments over the past half century or more in the theory of imperfect and asymmetric information have only served to elevate this challenge in importance. Likewise have the essentially unbounded complexity of the choice options decision makers now face, the essentially limitless information available, and the ever growing list of relevant uncertainties. Failing to find a needle in a haystack does not reflect a preference for losing it.

Block and Marschak made a methodological proposal that can be seen as a pioneering call for economic data engineering. They stressed the need for new "basic observations", as close as possible to standard choice data, to better identify beliefs and utility. In addition to his role in introducing the random utility model, Marschak, 1953, pioneered in elevating identification problems to their central role in applied economics. Not surprisingly therefore, one can phrase the 
Block and Marschak challenge in these terms. The starting point is the standard modeling and measurement framework defined by the classical theory of utility maximization and deterministic choice data. Abstractly this can be specified as a triple $\left(M^{S}, D^{S}, f^{S}\right)$ with $M^{S}$ being the standard complete information model of preference maximization, $D^{S}$ the corresponding data class comprising deterministic choice, and the mapping $f^{S}$ pinning down the implications of any such standard model in this standard data,

$$
f^{S}: M^{S} \longrightarrow D^{S}
$$

As noted above, this triple is both identified (in that $f^{S}: M^{S} \longrightarrow D^{S}$ is 11 ), and testable (in that the range $f^{S}\left(M^{S}\right)$ is a strict subset of $D^{S}$ ). What Block and Marschak called for is development of a new standard modeling and measurement framework $\left(M^{N S}, D^{N S}, f^{N S}\right)$ nesting the standard one, in which beliefs and preferences can ideally be identified, and which is ideally testable. I now introduce just such a framework drawing on ideas from recent applied work on mistakes and from the psychometric tradition.

\subsection{State Dependent Stochastic Choice Data (SDSC)}

In applied work, the smoking gun for inattention is the apparent failure to respond to underlying realities. In Chetty, Looney, and Kroft, 2009 the difference in demand when sales taxes are added at point of sale as opposed to when they are explicitly included in the sticker price reveals that they were largely ignored in the former condition. Likewise inattention to an available scholarship is identified by the difference in college acceptance when it is and when it is not highlighted (Hastings and Weinstein, 2008, Hoxby and Turner, 2015). This key idea also lies behind the psychometric tradition dating back to Weber, 1834. Classical psychometric experiments involve discriminating between stimuli. The Weber-Fechner laws relate objective differences in such stimuli to the subjective ability to discriminate between them. With hand-held weights, for example, the ability to correctly identify the heavier object has been shown to be based on their relative magnitude.

What makes the psychometric interpretation compelling is the obvious theory that failure to identify the heavier weight reflects the mistaken belief that it is in fact heavier rather than a desire to get the answer wrong. What makes it harder to identify mistakes in general decision problems is that, in addition to information being imperfect, preferences are unknown to the econometrician. The challenge is to specify a choice-based data set that helps in separately identifying utilities over prizes and beliefs about states of the world. State dependent stochastic choice data (SDSC) responds to this challenge by generalizing the psychometric method. Viewed abstractly, psychometric experiments measure how patterns of stochastic choice respond to changes in the underlying state of the world. The natural generalization is then to measure how patterns of stochastic choice depend on the underlying state of the world as observed by the econometrician. 
Caplin and Martin, 2015, formalize use of such ideal SDSC to operationalize the Blackwell model. There are two ground rules. First, key model elements are treated as commonly understood by the decision maker and the econometrician: the possible states, $\Omega$, the available actions, $A$, and the state dependent consequences, $z(a, \omega)$. Second, the econometrician is assumed to observe choices from this fixed decision setting infinitely often with different realized states of the world drawn from a fixed prior $\mu$. In this setting, state dependent stochastic choice data comprises a joint distribution over actions and states, $\mathbf{P}(a, \omega)$ (bolded as a data object). In using this data to make inferences about what the decision maker knows and likes, Caplin and Martin assume rational expectations. This means that the empirical frequency of states defines the decision maker's "revealed prior" $\mu_{\mathbf{P}}(\omega)$, which itself reflect the theoretical prior,

$$
\mu_{\mathbf{P}}(\omega)=\sum_{a \in A} \mathbf{P}(a, \omega)=\mu(\omega) .
$$

\subsection{Revealed Experiment and NIAS Inequalities}

What can SDSC reveal about the underlying utility function and beliefs of the decision maker? Consider first the psychometric case in which what is measured is not directly a belief but rather the proportion of times the heavier weight is chosen. Suppose that choice of left and right hand both correctly identify the heavier weight $90 \%$ of the time. With rational expectations, the average belief of the subject that that their choice is correct at point of decision making can be inferred as $90 \%$. Caplin and Martin provide the general decision theoretic translation of this simple method of inference. The econometrician derives the "revealed posteriors (signals)" associated with any chosen action $a$ as,

$$
\gamma_{\mathbf{P}}^{a}(\omega):=\frac{\mathbf{P}(a, \omega)}{\sum_{\nu \in \Omega} \mathbf{P}(a, \nu)} .
$$

The "revealed experiment" is then defined as the associated probabilities $Q_{\mathbf{P}}$ over revealed posteriors, which satisfy the Bayesian constraint by construction,

$$
\sum_{\gamma_{\mathbf{P}}} \gamma_{\mathbf{P}} Q_{\mathbf{P}}\left(\gamma_{\mathbf{P}}\right)=\mu_{\mathbf{P}}
$$

Note that there are definite limits on what the econometrician can infer from SDSC about the subjective Blackwell experiment. For example, it may be that the decision maker is more subjectively certain in some instances than in others when making a given choice. Such variations in subjective beliefs are not revealed in SDSC, which by its nature involves averaging. In formal terms, the revealed experiment is the least Blackwell informative experiment that produces the data (Caplin and Dean, 2015).

The most important question is what SDSC teaches us about the utility function. The answer turns out to be simple, intuitive, and illuminating. An obvious necessary condition for existence of a non-trivial rationalization is that 
there be no wholesale switches of action that are improving. Formally, the "no improving action switch" (NIAS) conditions are linear inequalities that any rationalizing utility function must satisfy. A fine point is to rule out the trivial rationalization by the utility function that induces global indifference.

No Improving Action Switches (NIAS): Given decision problem $(\mu, A)$, data set $\mathbf{P}$ satisfies NIAS if there exists a non-trivial utility function such that,

$$
\sum_{\omega} \mathbf{P}(a, \omega) u(z(a, \omega)) \geq \sum_{\omega} \mathbf{P}(a, \omega) u(z(b, \omega))
$$

all $a, b \in A$.

That this is necessary is clear from the observation that the decision maker is presumably able to identify all subjective conditions that give rise to a given decision, and switch in all such conditions to any available alternative. Caplin and Martin show existence of a utility function satisfying NIAS to be not only necessary but also sufficient for the data to be rationalizable by Bayesian expected utility maximization. While simple, the NIAS inequalities have rich content. We illustrate this in section 6.5 below when discussing welfare comparisons of different methods of presenting a given choice set.

\subsection{Rational Inattention, NIAC, and Recovery}

What decision makers know depends on how hard they try to learn. This depends both on how important they believe the resulting understanding will be and how hard they find it to learn. Rational inattention theory captures this trade-off between the costs and the benefits of learning (Sims, 1998, 2003). In the general model, costs can differ across priors as $K(\mu, Q)$, where $Q$ is a generic Bayes' consistent distributions of posteriors. Choice of what to learn is modeled as maximizing the resulting prize-based expected utility less costs of learning,

$$
V(\mu, Q)=\sum_{\gamma} \hat{u}(\gamma) Q(\gamma)-K(\mu, Q)
$$

where $\hat{u}(\gamma)$ is the maximized level of utility at posterior $\gamma$. The utility function can either be treated as understood in the simplest of cases or itself be inferred to the extent possible, as warranted by the application.

Interestingly, SDSC can operationalize rational inattention theory as it can basic Bayesian decision theory. The distinction is that one has to observe a richer class of decision problems. This is just as in standard revealed preference theory, which is rendered testable only if one observes choice from distinct decision problems. Caplin and Dean, 2015, consider SDSC from a set of distinct decision problems that share the same prior to derive testable implications and to identify rationalizing utility functions. The idea of their test is imported from production theory. Just as factories can be moved between locations in the model of Koopmans and Beckmann, 1957, so attention strategies and their revealed experiments can be moved between decision problems. So porting them 
has no impact on total costs and so should not raise total utility. Technically there should be no improving cycles of revealed experiments across decision problems. The following is an inclusive version of the "no improving attention cycles" condition that incorporates NIAC as well. The main result is that this can be used to fully characterize data sets consistent with rational inattention as well as all rationalizing utility functions.

No Improving Attention Cycles (NIAC): SDSC for a collection of decision problems satisfies NIAC if there exists a utility function $u$ such that, given any cyclic list of observed decision problems $A_{m}$ for $1 \leq m \leq I$ with $A_{1}=A_{I}$,

$$
\sum_{m=1}^{I-1} E U\left(A_{m}\right) \geq \sum_{m=1}^{I-1} \sum_{a_{m} \in A_{m}} \max _{a_{m+1} \in A_{m+1}} \sum_{\omega} u\left(a_{m+1}, \omega\right) \mathbf{P}_{m}\left(a_{m}, \omega\right),
$$

where $E U\left(A_{m}\right)$ is expected utility implied by $u$ given the observed data $\mathbf{P}_{m}$ in choice set $A_{m}$.

Note that the operation on the right hand side expresses the optimal utility that can be achieved using action choices from $A_{m+1}$ in the data associated with $A_{m}$. The idea is that, given any observed action $a_{m} \in A_{m}$, one looks in set $A_{m+1}$ and picks some action to replace it wholesale and computes the corresponding expected utility. One then adds this up across all actions $a_{m} \in A_{m}$ that are chosen in the data. Any such set of wholesale action replacements is feasible. The optimal replacement is the one that maximizes expected utility among all such options. Note also that this conditions nests NIAS if we consider cycles of length one in which $A_{1}=A_{2}=A$.

This inclusive version of NIAC is obviously necessary for existence of a CIR representation. The key result is that it is also sufficient. There are simple ways to work with these inequalities, which remain largely unexplored. Note also that NIAC is analogous with the strong axiom of revealed preference. This analogy operates both at the intuitive and at the formal level (Pattanayak and Krishnamurthy, 2021).

The strong links between rational inattention theory and classical theories of production and consumption are striking. Perhaps we should have expected this. In the information age, the classical separation of production and consumption is archaic. What a smartphone offers in terms of consumption services depends on the technical abilities of the purchaser. Having low costs of learning impacts what is produced when using a given machine, which then forms part of consumption. Another concrete reflection of the analogy between attention costs and production theory is the recovery result of Caplin et al., 2020. Recovery is based on a precise analogy with use of the price equals marginal cost condition to recover the cost curve of a competitive firm. Costs are recovered by varying the probability of implementation of prizes just as the linear scaling of price allows a competitive firm's supply curve to be recovered. 


\subsection{Special Cost Functions}

There is increasing awareness of how the form of the cost function impacts behavior. The starting point is the function based on the expected reduction in Shannon entropy, which is remarkable in its subtlety, supplety, and elegance. Up to a linear scaling factor it can be written as,

$$
K(\mu, Q)=H(\mu)-\sum_{\gamma} Q(\gamma) H(\gamma)
$$

where $H(\gamma)=-\sum_{\omega} \gamma(\omega) \ln \gamma(\omega)$ is the corresponding Shannon entropy.

The behavior implied by this cost function is special in many respects. For example it implies that discrimination between states depends on payoffs alone, not frequencies (Woodford, 2012, Shaw and Shaw 1977). It also implies that there is equal perceptual distance between all states. As research on attention has advanced, so has the search for alternative cost functions that generalize the Shannon model to better match behavioral deviations on a case-by-case basis. Many well-studied generalizations are "posterior separable" (Caplin and Dean, 2013, Caplin, Dean, and Leahy, 2021). Posterior separability generalizes the Shannon form to allow for an arbitrary convex function $T_{\mu}(\gamma)$ that can depend on the prior,

$$
K(\mu, Q)=T_{\mu}(\mu)-\sum_{\gamma} Q(\gamma) T_{\mu}(\gamma)
$$

Uniform posterior separability restricts $T_{\mu}(\gamma)$ to be common for all priors with the same support. Such utility functions are of growing interest as recent work of Hébert and Woodford, 2019, Morris and Strack, 2019, and Bloedel and Zhong, 2020, has shown equivalence between the information that is acquired through a process of continuous updating and optimal stopping, and the information acquired in a static model with a cost function in the uniformly posterior-separable class. Behaviorally, such cost functions must satisfy a condition known as locally-invariant posteriors (Caplin, Dean, and Leahy, 2021): revealed posteriors must be chosen for all priors in their convex hull. Dean and Neligh, 2019 find some support for this pattern of behavior. Further in support of application, Miao and Xing, 2019, have developed dynamic progamming methods for uniformly posterior separable cost functions as the chosen posteriors today become the priors tomorrow. Moreover Hébert and Woodford, 2020 , provide a family of uniformly posterior-separable cost functions that can accommodate the notion of perceptual distance.

Other important cost functions are "invariant". This class is defined by strong cross-state symmetry conditions. They are important in macroeconomic applications e.g. ruling out inefficiencies in Hébert and La'O, 2020, and Angeletos and Sastry, 2019. Behaviorally, Caplin, Dean, and Leahy, 2021, show that a posterior separable cost function is invariant if and only if the distribution of payoffs is a sufficient condition for observed behavior. Remarkably, the only uniformly posterior separable cost function that is also invariant is the Shannon cost function. 
While the Shannon model and its posterior separable generalizations will be central in the coming decades, there are reasons to cast an even wider net. One restrictive aspect of the Shannon model is that the response of attention to large incentives is often significantly smaller than would be implied by the response to small incentives (Caplin and Dean, 2013). Csaba, 2021, introduces invariant cost functions that are not posterior separable, based on the information radius of Sibson, 1969, and that allow for general attentional elasticities of learning with respect to incentives. They can be solved explicitly using a version of the standard Blahut-Arimoto algorithm. The moral is that general forms of entropy may be of great value in economics just as in other disciplines (Tellenbach, et al., 2009, Gell-Mann and Tsallis, 2004).

\section{Mistaken Decisions and SDSC: Applications}

By its nature, data engineering sets ambitious targets for measurement. In the case of SDSC this target is increasingly in reach. In this section I outline case studies that show the high potential of such research. At the same time, I show how the model-centric approach that is economic data engineering opens new areas of applied research.

While first economic examples of SDSC being gathered were based in the experimental laboratory (e.g. Ambuehl, Ockenfels, and Stewart, 2018, Bronchetti et al., 2020, Caplin and Dean, 2013, Caplin and Martin, 2016, Dean and Neligh, 2018, Khaw, Stevens, and Woodford, 2017), I focus in this section on field research. In section 3.1 I outline case studies ranging from the recreational (umpiring baseball) to matters of life and liberty (medical and judicial decisions). Section 3.2 outlines research on discrimination, while section 3.3 covers research on feedback effects between economic deprivation, attentional resources, and income. As these and other branches of applied research advance, so pressure is building to correspondingly enrich modeling of attention constraints in the co-evolutionary manner of data engineering. Section 3.4 focuses on the importance of better modeling and measuring dynamic patterns of learning and incomplete subjective awareness of costs. Section 3.5 outlines applications of information-theoretic data engineering to what will surely become the most important decision makers of all in the near future: machine learning algorithms.

\subsection{From Ball-Field to Operating Table}

For SDSC to be available, the econometrician must observe choices whose payoffs depend on facts that the decision maker may or may not have taken in. Such choices must be observed frequently for different realizations of the underlying facts. These conditions are well met in numerous work tasks. Umpiring and refereeing calls in sporting events represent a paradigm case. For example in baseball and in basketball, filming of games means that there is essentially 5050 vision in hindsight. Making accurate calls is of clear payoff relevance, since umpires and referees are judged and ultimately rewarded based on reviews of 
their performance.

Archsmith et al., 2021, exploit high-frequency data on the accuracy of umpires' calls in Major League Baseball. They also develop a model of the importance of each call based on pivotality (e.g. the chance that a mistake would significantly change the balance of play). They find that umpires make fewer mistakes in higher stakes decisions. They also observe a pattern of increased mistakes after important decisions, as if effort applied to earlier decisions raises costs of attending to later decisions. They go so far as to identify how breaks in the game at the end of each inning impact performance. Such breaks remove the negative spillover from high stakes decisions to those of lower stake. Finally, they find evidence of anticipatory shepherding of resources. They show that an expectation of higher stakes in upcoming decisions leads to more errors in current decisions, consistent with forward-looking behavior by umpires aware of attention scarcity. While many of these findings are spiritually in line with classical production theory, the roles of tiredness per se and the impact of expectations represent a particularly human aspect of the theory. Bhattacharya and Howard, 2021, consider more strategic aspects of baseball, again with findings that broadly align with rational inattention.

Turning to matters of life and death, a 1999 Institute of Medicine Report suggests that more than 40,000 people in the United States die because of medical errors (Donaldson, Corrigan, and Kohn, 2000). There is every reason to believe that expert review would identify many of these errors, a necessary step in rectification. Yet few if any public data sets are available. In the meantime the best we can do is study indirect evidence of attentional depletion and resulting mistakes. For example Gandhi et al., 2006, used the data on malpractice claims against doctors to document and describe diagnostic errors.

Researchers are starting to find work-arounds. Particularly well developed is the work of Currie and Mcleod, 2017, who use standard administrative data to study C-sections to identify doctors whose decision making is significantly worse than the norm. Birth records contain detailed information about health conditions that is of use in assessing the quality of decision making as well as execution of that decision. Currie and Mcleod use machine learning techniques to look at the diagnostic characteristics that predict success of the treatment in large scale administrative data. Their results suggest not only that there may be too many $\mathrm{C}$-sections being performed on low-risk women but there may be too few C-sections being performed on high-risk women. Their model allows them to separately quantify the effects of procedural choice and surgical skill. More generally, their approach shows the high potential for use of administrative health databases to identify mistaken medical decisions and to make changes that would improve patient health outcomes.

Often of equivalent importance to medical decisions, and equally understudied, are legal settings. Cameron and Kornhauser, 2006, and Stephenson, 2010, argue that error reduction is a key element in the design of the legal systems, with appeals processes a key case in point. Pioneering work by Shavell, 1995, suggests that the very existence of the appeals process provides incentives for trial court judges to properly dispose cases. Typically such appeals impose 
time and reputational costs on the responsible parties, in line with the broader argument that error reduction is a key element in the design of the legal system. What makes legal cases particularly sophisticated is difficulty in identifying the underlying state: e.g. guilt or innocence. An ongoing study in the Mexican Labor courts shows that a clarifying intervention (adding an index to the case file) significantly lowered the number of successful appeals (Caplin, Gomberg, and Sadka, 2021). Yet identifying features of a case file that makes the verdict less easy to appeal requires great legal expertise. Another legal case study introduces method of partial identification and adapts the NIAC conditions to develop general conditions under which systematic prediction mistakes can be identified in observational settings with application to pretrial release decisions in New York City (Rambachan, 2021).

\subsection{Discrimination in Hiring and Other Decisions}

Understanding sources of discrimination between in- and out-groups and reducing its extent are among the most pressing policy issues of our time. The central distinction in the literature is between preference- and belief-based channels of discrimination. Pure preference-based discrimination occurs when the decision-maker obtains different utility from outcomes depending on group identity (Becker 1957). Pure belief-based (statistical) discrimination occurs when decisions differ across groups because a decision-maker holds different beliefs about each group (Arrow 1972; Phelps 1972). As so often, what has bedevilled this research is the fact that beliefs and preferences are confounded in standard choice data.

Recent research provides several promising avenues forward that involve data engineering. In resume studies (Bertrand and Mullainathan, 2004), the researcher generates SDSC by designing resumes differing in only one fact: the signalled ethnicity of the applicant. In their experiment, names that strongly signal gender and race were randomly added to fictitious resumes. When these resumes were sent to prospective employers, they observed a strong disparity in callbacks for a given quality of resume depending on the race of the name applied to that resume. Likewise Reuben, Sapienza, and Zingales, 2014, found that employers in a lab experiment are less likely to hire a female candidate to complete a task in which males and females perform equally well.

In terms of theoretical enrichment, Bertrand and Mullainathan suggest that a large part of the explanation for their findings works through an attentional strategy of reading no further in a c.v. when an employer sees an AfricanAmerican name. A corresponding rational inattention model of discrimination is developed by Bartoš et al,. 2016. The theory suggests an interesting distinction between markets involving lemon-dropping (e.g. application for rental housing) as opposed to cherry picking (application for a job). Their findings are consistent with a model of endogenous allocation of costly attention, in which higher such costs magnify the role of prior beliefs. Since their channel is attentional, Bartoš et al., 2016 also engineer data on actual information acquisition. They find that negatively stereotyped minority names reduce employers' effort to inspect 
resumes. In contrast, minority names increase information acquisition in the rental housing market.

While some discrimination is attentional in origin, this does not mean that it is purely belief-based. Recent research of Martin and Marx, 2021, suggests that there is in addition a significant amount of pure taste-based discrimination. Their test uses information-theoretic data engineering explicitly. The fact that the basic data comes in the form of SDSC allows them to develop an NIASbased test to identify taste-based discrimination regardless of what is or is not learned from the resumes. Applying this test to the lab experiment of Reuben, Sapienza, and Zingales, 2014, they provide robust evidence of prejudice: in one of the treatments rejected women were more productive than hired men so a wholesale switch would have raised payoffs. They also revisit the field experiment of Bertrand and Mullainathan, 2004, and find that the probability of a callback for an African-American male decreases with resume quality. This provides strong evidence that employers are prejudiced in their selection motive regardless of what information they internalized from the resumes they received.

\subsection{Poverty, Attention, and the Speed-Accuracy Trade-off}

Mani, Mullainathan and Shafir, 2013, argue that poverty affects income-earning capacity through a variety of channels that deplete attentional resources and negatively impact job performance. In support, Kaur et al., 2021 paid poor subjects a piece rate for completing a repetitive yet intricate attention-demanding task. They found that workers who were paid earlier were better able to complete these tasks and consequently earned higher income. Other poverty-related factors that have been found to affect attentional constraints and income are sleep deprivation (Bessone et al., 2019), exposure to high levels of air pollution (He, Liu, and Salvo 2019), and exposure to high levels of noise pollution (Dean 2019).

An important next step in this research is quantification of the various effects that have been identified. In engineering the appropriate data set, one wants to see tasks repeated with markers not only for these measurements but also task performance by time of day, time since last break, etc. What makes the corresponding engineering more challenging is that there is no solid model of how psychological states interact with costs of attention. At least in the early days, this is likely to be somewhat atheoretical measurement. Going even further afield, there are channels by which hedonic psychological states, such as happiness, might impact attention (Kahneman, Wakker, and Sarin, 1997; Rayo and Becker, 2005; Benjamin et al., 2012). Köszegi and Rabin, 2008, make the data engineering case that adding such measures to behavior is potentially of great value in revealing preferences themselves.

A particularly relevant feature of work settings in the field is the routine ability of the econometrician to observe decision times. These have a distinguished history of psychometric study (Donders, 1868, Luce, 1986), and are increasingly becoming subjects of research in economics (e.g. Wilcox, 1993, Kocher and Sutter, 2006, Rubinstein, 2007, Chabris et al., 2009, Kahneman 
and Egan, 2011, Schotter and Trevino, 2013, Spilliopoulos and Ortman, 2014, Achtziger and Alos-Ferrer, 2014, Geng, 2015). The speed-accuracy trade-off is particularly pertinent. From a theoretical perspective an obvious starting point involves emerging models of optimal stopping with costs of learning as in Hebert and Woodford, 2019, 2020, Morris and Strack, 2019, and Bloedel and Zhang, 2020. Another theoretical tradition is the drift-diffusion model of psychology (Ratcliff, 1978, Ratcliff and McKoon, 2008), variants of which are increasingly making their way into economics (see Fehr and Rangel, 2011, Krajbich and Rangel, 2011, Krajbich et al., 2012, Fudenberg, Strack, and Strzalecki, 2018, and Caplin and Martin, 2016). A non-standard implication of the driftdiffusion model is prevarication: that choice among options that are of similar utility take a long time. Alós-Ferrer, Fehr, and Netzer, 2021, develop a complete model along these lines.

A reasonable conjecture is that interacting time to decide with choice process data may allow for separate identification of classical models of costly learning and models with prevarication. Choice process data captures provisional choices during the search process and can be generated experimentally (Campbell, 1978, Caplin and Dean, 2011, Caplin, Dean, and Martin, 2011, Agranov, Caplin, and Tergiman, 2015, Recalde, Riedl, and Vesterlund, 2017). The smoking gun for the prevarication effect might be a prolonged period of rapid switching between options in the time shortly before finalizing selection. Other promising avenues for future research involve ongoing efforts of both economists and psychologists to develop decision theoretic models of visual attention such as the work of Krajbich, 2011, Rangel, Fehr and Rangel, 2011, Krajbich et al., 2012, and Callaway, Rangel, and Griffiths, 2020. As might be expected, these ongoing developments involve increased collaboration between economists and psychologists, who have studied visual behavior at great depth (Carrasco, 2011).

\subsection{Learning, Awareness, and Income}

In almost all of the cases that have been studied in detail, the decision makers have much practice in the class of task studied, be it umpiring in baseball, performing a routine operation, etc. Of course these are skills that have to be learned: one would expect mistakes to be reduced over time. In model terms, this corresponds to a reduction in learning costs. An important challenge for modeling and measurement is to better capture the nature of these reductions at all stages in the learning process. As one part of this there is a need to formulate more general versions of the information-theoretic model of learning by doing of Jovanovic and Nyarko, 1994, and map these to corresponding dynamic patterns in the structure of mistakes.

A related challenge is to properly measure the outputs of the teaching process. One can view a large part of education through the learning by doing lens as designed to reduce costs of learning and aid in later decision making. In principle exams are designed in large part to assess whether such costs have been lowered for new problems that should be answerable if the teaching succeeded in lowering costs of comprehension. Unfortunately, there is at present 
little systematic social scientific research on effectiveness in this dimension. All multiple choice exams generate coherent and valuable data that could be used to estimate models of learning, yet this data essentially ends up on the cutting room floor. A first step in the direction of improvement would be retain and analyze such data in multiple dimensions. Going beyond this, the exams themselves could be re-engineered to make the data they produce more insightful. A simple version of this point was made long ago by De Finneti, 1965, and Savage, 1971, who argued at a minimum for allowing students to answer questions probabilistically, a method that had already been shown to work for weather forecasting (Brier, 1950).

There are many important open questions related to skills that are remunerated in the workforce. How costs of comprehension develop over the course of the life-cycle and whether there is also a more abstract sense of decision making skill that can be developed are important open questions warranting further data engineering. Deming, 2021, presents suggestive evidence of the importance of decision-making skills for the trajectory of life-cycle earnings. He models these skills as taking longer to accumulate in high variance, non-routine jobs. His findings suggest that life-cycle wage growth in decision-intensive occupations has increased over time, and it has increased relatively more for highlyskilled workers. Further operationalizing these links is an important next step in information-theoretic data engineering. Need for a more granular assessment of the skills that drive income over the life-cycle is clear both in human capital theory, which leaves this as something of a black box and in the empirical literature linking non-cognitive skills to lifetime earnings (Heckman and Rubinstein, 2001).

Another set of important open questions for modeling and measurement relate to subjective awareness of costs of learning and of patterns of mistaken decisions. There is little reason to believe that individuals can accurately assess the difficulty of novel tasks. There are many sophisticated aspects to model and measure in the area of partial awareness. For example, one role of practice may be to increase awareness of costs. The case above of experienced umpires shepherding resources for important later decisions illustrates this well. Analogous issues of awareness show up at the life-cycle scale. Cognitive decline surely raises costs of comprehension and errors made in many settings, and here again issues of awareness appear to be crucial. Not all are aware of their state of decline, and many in the pre-decline phase are aware that they may later not be so aware. I discuss this again in section 6.5 in the context of reluctance to relinquish control of financial assets at the appropriate time.

One method of engineering data to gain insight on awareness of costs involves allowing choice of tasks in which higher attentional complexity is rewarded by higher levels of possible payout. For example one might offer one option that is informationally simple yet offers little reward, and a second that is more challenging yet offers high reward. Experiments along these lines have been conducted by Avoyan and Romagnoli, 2019, Carvalho and Silverman, 2019, and Bronchetti et al., 2020. Further data engineering to model and measure subjective awareness of costs in the field is of high priority. Possibly relevant 
evidence is provided by Kaur et al., 2021, who note the value that mid-day breaks have in terms of raising productivity, yet failure of workers to take, and firms to provide, such breaks.

\subsection{What Machines Learn and Why}

Machines are able to outperform humans in making a wide array of predictions, so have replaced humans in predicting if a driving route has a low expected travel time, an eye scan shows physical damage, a manufactured product has a defect, a house for sale is a likely match, internet activity is a security threat, an email is spam, and so on. This is giving rise to an emerging economic literature on use of algorithms, such as that of Kleinberg et al., 2015, on bail decisions. Yet there remain important gaps to close between the prediction-based approach in machine learning and more causal approach to modeling in social science (Hofman et al., 2021).

To phrase the challenge in its simplest terms, there is an issue of interpretation. What do machines learn well, what badly, and why? When are the resulting predictions equitable? If they are not, in what ways are they inequitable? Even if an analyst knows all of the code behind an algorithm, it is nearly impossible to fully grasp its inner-workings. This challenge is exacerbated by increasingly complex training protocols, an exploding number of parameters, and the widespread adoption of nested algorithms. In fact, machines are able to increasingly outperform humans in part because of the lack of structure imposed on their learning ex ante. However, this "black box" nature of algorithms has problematic aspects. For example, it makes it hard to assess how machine learning lowers information frictions and why machine learning results in discriminatory predictions. These issues are related to the explainability question/challenge and miscalibration as presented in Guo et al., 2017.

An important underlying issue is that machine "learning" is not learning in the classic Bayesian sense. Machine learning uses complex algorithms to select model parameters for making predictions. By contrast, Bayesian learning involves generating and processing signals about an uncertain state. Going forward, there is great value in bridging this gap. Information-theoretic data engineering provides a rigorous approach to recovering the learning costs implicit in machine learning algorithms. The first step is to translate the SDSC data that the machine produces into a revealed experiment and thereby identify what the machine learns, along the lines laid out in section 2.2 above. At this stage the results sketched in section 2.3-2.5 linking properties of the data to implied costs of learning can be applied, in particular the results of Caplin, Dean, and Leahy, 2021. These provide new methods for constraining cost functions and understanding what these constraints say about the functional form of costs.

There are two key applications in ongoing research in this area (with Daniel Martin and Philip Marx). First there is the issue of how machines reduce information frictions in the economy. The way in which available information is incorporated - or not incorporated - into decision-making is key to understanding business fluctations, stock prices, and economic growth (Jones and 
Tonetti, 2020, Veldkamp, 2020). One specific technical question that can be addressed using methods of information-theoretic data engineering is whether or not adding layers to deep learning neural nets lowers learning costs and moves learning costs in line with Shannon mutual information, which has so many ideal properties. With regard to discrimination, the reasons why otherwise identical agents receive differential treatment is key to understanding heterogeneity in economic outcomes. In many settings we must now shift focus to understanding the constraints on learning that machines face and the reasons why individuals belonging to distinct demographic groups are assessed differentially by machines. For these reasons and more, the application of information theoretic data engineering to machine learning is of highest potential.

\section{Life-Cycle Data Engineering: Survey Design}

Separation of beliefs and preferences is particularly important and challenging in estimation of life-cycle models. In section 4.1 I outline the strong identifying assumptions that are often invoked in model estimation, such as rational expectations and ex ante homogeneity. There is a growing consensus that innovative quantitative survey instruments can play an essential role in resolving these identification problems. Section 4.2 covers measures of unconditional and conditional probabilistic beliefs about future outcomes, such as earned income. Section 4.3 highlights the combination of such questions with direct stated preference questions to uncover both beliefs and preferences, with application to educational and career choice. Section 4.4 covers strategic survey questions (SSQs), which are stated preference questions in which the counter-factual scenarios are tied tightly to formal model objects that must be carefully explained to respondents. Section 4.5 highlights the challenge of engineering survey instruments that can be intuitively understood by respondents who are not formally trained.

\subsection{Life-Cycle Models and Identification Problems}

Appropriately specified life-cycle models are capable of capturing the interplay of forces that impinge on decisions and outcomes in a vast array of settings. The life-cycle framework is of ever growing importance as economists increasingly study patterns of saving, earnings, labor market decisions, health expenditures, asset holdings, debt levels, and more, over the life course. In typical applications, the only forces at work are preferences and beliefs. What accounts for the framework's flexibility is that preference parameters can cover so many factors: the discount rate, risk aversion, precautionary motives, bequest motives, labor-leisure trade-offs, health-state dependent utilities, etc. Likewise uncertainty comes in many flavors, relating to labor income, asset returns, returns to education, availability of benefits, health states, etc. I view this burgeoning literature as a long essay on how remarkably rich are the insights that preferences, beliefs, and their interplay can provide for rationalizing all manner of economic 
and other outcomes over the life-cycle.

With all the implied richness in the specification of preferences, beliefs, and their interaction comes a natural challenge: that of model identification. In most applications there are many alternative models that can equally well explain life-cycle patterns in administrative data: particular cases will be outlined below, but the challenge is ubiquitous. It is traditional absent survey data to impose strong and unrealistic identifying assumptions on beliefs, such as full information rational expectations. Manski, 2004, is explicit in pinpointing the preference/belief identification problems:

"Observed choices may be consistent with many alternative specifications of preferences and expectations, so researchers commonly assume particular sorts of expectations. It would be better to measure expectations in the form called for by modern economic theory; that is, subjective probabilities." Manski 2004, p. 1329

Not only does one need to specify relevant aspects of utility and underlying states of the world, but also one has impose strong homogeneity assumptions due to data constraints, as Dominitz and Manski, 1997, stressed:

"The studies to date universally assume that expectations formation is homogeneous; all persons condition their beliefs on the same variables and process their information in the same way." Dominitz and Manski, p, 856 .

Life-cycle data engineering reflects the emerging consensus that survey instruments that measure beliefs and preferences can both help resolve the basic preference/belief identification problem and allow for heterogeneity.

\subsection{Conditional and Unconditional Beliefs}

What matters for choice of education, acceptance of job offers, retirement, and other decisions are beliefs about future income both in terms of expectations and in terms of variability, not simply ex post realizations. It is far from obvious that a standard behavioral data set of realized behaviors can identify such beliefs. Haavelmo, 1958, early on outlined the potential of enhancing measurement of expectations. This was also top of mind for Manski, 1990, in motivating the modern literature on measuring probabilistic expectations for models of lifecycle behavior.

Under the leadership of Richard Suzman, Tom Juster, and Bob Willis, expectations questions have regularly been posed in the Health and Retirement Study. After more than 25 years of investigation, it is now clear that quantitative expectations questions reveal new and valuable information. Manski, 2004, and Hurd, 2009, summarize important findings concerning survey-measured probabilities, including their broad internal consistency and connection with external reality. For example, Hurd and McGarry, 2002, show that individuals and groups with higher subjective survival probabilities live longer. Hurd and Rohwedder, 2012, 
and Kézdi, and Willis, 2011, link beliefs about stock holding to actual portfolio holdings. Van der Klaauw, 2012, highlights the value of expectations data for structural modeling.

An early application, and a particular area of focus in this review, concerns measuring expectations of income, areas in which Dominitz and Manski, 1997 pioneered. They elicited probabilistic estimates of the cumulative distribution of total household income, before taxes, over the next 12 months. After posing questions on the maximum and the minimum possible values, they asked for several points on each respondent's subjective cumulative distribution. They provided basic credibility checks of the implied subjective mean and variance based on realized income, age, and employment status, and highlighted heterogeneity. Dominitz and Manski, 1996, also provided early evidence that student expectations of returns to schooling impact their educational choices. Again, basic credibility checks were passed in terms of patterns of earnings and also in terms of high levels of subjective uncertainty. This form of conditional expectation question has since been refined and found to be of significant predictive value in a number of other settings. For example Hurd and McGarry, 1995, 2002, study questions that were posed in the Health and Retirement Study related to retirement conditional on health. Individuals report significantly earlier retirement should their health deteriorate, and the record confirms this difference in ex post outcomes.

\subsection{Stated Preferences}

Recent research has picked up on the early investigation of Dominitz and Manski, 1996, relating income expectations to schooling. Wiswall and Zafar, 2021, study how individuals believe human capital investments will affect their future career and family life. They find evidence of students sorting into majors based on perceived ex ante returns and family expectations. In a follow-up survey conducted six years later, they find a close connection between the expectations and realizations.

The fact that family expectations impact choice of major and career is not surprising. What it suggests is the value of independently investigating preferences as well as beliefs. This requires development of some form of stated preference instrument. These have a distinguished history in economic analysis separate from expectations questions. Ben-Akiva, McFadden, and Train, 2015, detail both our current understanding and the origins of this work, in particular the work of Luce and Tukey, 1964. Use of stated preference instruments in estimation of economic models was pioneered in the discrete choice literature by Brown and Rosen, 1982. They considered households choosing between neighborhoods offering different bundles of amenities (schools, shops, parks, tax rates, parks, etc.). Given the small number of options and the many differences between them, they developed stated preference questions to pin down the relative importance of different such attributes. Use in economics took off when McFadden, 1986, showed how stated preference measures could be analyzed using the tools of discrete choice analysis. 
It is now standard in the broader discrete choice literature to use surveybased stated preference methods to help overcome identification problems. Blass, Lach, and Manksi, 2010, and Kesternich et al., 2012, confirm the information content of well designed such questions in various economic contexts, as do Hainmueller, Hangartner, and Yamamoto, 2015, in the political context. Bernheim et al., 2013, and Cao and Zhang, 2021, develop experimental methods for extracting and boosting the information content of stated preferences for revealed preferences.

In the life-cycle context, Arcidiacono et al., 2014, pose survey questions to undergraduate students relating to beliefs, stated preferences, and probabilities of choosing particular occupations. They find large differences in expected earnings across occupations, and substantial heterogeneity across individuals in the corresponding ex ante returns. They find that many individuals are willing to give up substantial amounts of earnings by not choosing their highest-paying occupation. Likewise Wiswall and Zafar, 2018, use stated preference questions to estimate students' preferences for workplace attributes. These job preferences relate to college major choices and to actual job choices reported in a follow-up survey several years after graduation. They focus in particular on gender differences in preferences for work flexibility, job stability, and earnings growth. They find that gender differences in such preferences explain a significant portion of the early career gender wage gap.

\subsection{SSQs, Supply Curves, and Arrow Securities}

The life-cycle framework pins down behavior in all model-consistent contingencies. That is why it is of value in counter-factual analysis and in policy analysis. By contrast, behavioral data relates only to realized contingencies. It seems far-fetched to believe that historical data will be rich enough to accurately assess the full set of counterfactual behaviors. This is no more credible a priori than would be a claim that medical histories are sufficient to predict responses to all possible medical interventions. This suggests the possible value of engineering targeted survey instruments to study what behavior would have been in important unobserved contingencies. This is the idea underlying design of "strategic survey questions" (SSQs). The first step in developing such questions is to specify a substantive economic question of applied interest, the state of the art corresponding model, and the identification challenges associated with use of standard forms of data to estimate this model. The second step is to pin down contingent behaviors that were not realized in the behavioral record, yet would have been particularly useful for model identification had they been. The third step is to engineer corresponding SSQs by setting up the identifying scenarios meaningfully and posing the corresponding questions.

A first form of SSQ is designed to reveal preferences that would be visible were markets to be complete and financial instruments perfect. This use of SSQs based on specifying availability of Arrow securities is well illustrated in the recent literature on wealth holding in later life (Dynan, Skinner, and Zeldes, 2002, De Nardi, French, and Jones, 2009, 2010, 2016, and Ameriks et al., 2015, 
2020). For those with relatively high wealth at retirement, the basic life-cycle model of Modigliani and Brumberg, 1954, predicts that it should be run down over the retirement years, when income is low. The puzzle is that wealthy older households do not spend wealth down in retirement as predicted. Smith, Soto, and Penner, 2009, Poterba, Venti, and Wise, 2010, 2011, Love, Palumbo, and Smith, 2009, and De Nardi, French, and Jones, 2016, show that household wealth is typically relatively stable at later ages.

What explains slow asset spend down in early retirement? One set of forces that have been analyzed extensively are bequest motives (Kotlikoff and Summers, 1981, Hurd, 1989, McGarry, 1999, Finkelstein, and McGarry, 2006, Kopczuk and Lupton, 2007). Lockwood, 2012, estimates that bequest motives can explain a significant portion of the continued high asset holdings of the elderly. Yet factors other than bequests clearly play a role. There has been particular focus on late in life expenses associated with deteriorating health and/or the need for long term care. De Nardi, French, and Jones, 2009 and De Nardi, French, Jones, and McCauley, 2016, have documented high levels of late in life medical spending. Likewise, Poterba, Venti, and Wise, 2010, show that episodes of poor health result in significant run down of wealth. These possibly high expenses have a large effect on earlier spending if there are significant precautionary motives (Carroll, 2001, Attanasio and Weber, 2010, Gourinchas and Parker, 2002). Indeed, De Nardi, French, and Jones, 2010, estimate precautionary motives related to health risks to have a significant impact in slowing down spending in early retirement. Likewise Kopecky and Koreshkova, 2014, and Lockwood, 2012, estimate long term care expenses, which are somewhat distinct from standard health-related expenditures, to be significant drivers of savings. Pulling together the various strands of evidence, it is certainly plausible that precautionary motives associated with high medical and assisted living expenses play an important role in explaining slow wealth spend down.

In terms of model estimation, the ideal would be to separately identify bequest motives and precautionary motives to understand the forces impacting late in life spending. But an identification problem looms large, as originally noted by Dynan, Skinner, and Zeldes, 2002. Since markets are incomplete, wealth can be held for many reasons. If care motives are of the essence, then bequests are accidental results of spending less than feared on care. If bequest motives are of the essence, high care expenses are represent a failed effort to make a large bequest, rather than being a primary driver of wealth holding.

Noting precisely the key identification problems, Ameriks et al., 2015, 2020 design SSQs to separate preferences over resources dedicated to long term care from bequest motives. Several of these concern demand for Arrow securities that deliver resources in key contingencies. As in experimental economics, the goal in posing an SSQ is to be transparent. To illustrate what this means in practice, in one question in Ameriks et al., 2020, the topic is the trade-off between having resources when in need of long term care and when not in need of long term care. Respondents are told that this is the topic of interest. They are then asked to divide up a fixed wealth allocation between the two uses using "locked allocation boxes", which are effectively state dependent Arrow securities. They 
take a comprehension test in relation to this broad question as well as the precise allocation problem that they are faced with. Once the tests are passed, respondents go to a screen in which they are to make their allocation choice. They select the amount by moving a cursor along an allocation bar. Given that respondents have absorbed the fixed costs of understanding the allocation issue they are facing, it is repeated for different amounts of money. Answers are found to be highly correlated at the individual level, suggesting a consistent view of relative priorities. The combined answers are used in model estimation.

The substantive results in Ameriks et al., 2015, 2020 are qualitatively and quantitatively clear. Whenever decisions are faced on allocating funds to long term care, it is found to be a high priority. The same is not true for bequests. For example, many of the (upper middle class) respondents would not make any bequest at all if that subtracted from $\$ 100,000$ usable for one year of long term care. When interpreted through the lens of the model of long term care utility, this means that precautionary saving motives associated with long term care risk contribute significantly more to their late in life savings behavior than do bequest motives. Interestingly, this result is suggested even if one looks exclusively at standard behavioral data. The SSQs make the conclusion far more clear cut and quantitatively precise, and reveal in stark fashion how concerning are high costs of care. This and other complementary work has significantly shifted debate on the motives for holding wealth in later life.

A second case of this SSQ-based research method in practice involves estimating a labor supply curve applicable to a counter-factual scenario, specifically to uncover the extent to which older Americans might work longer were jobs to change in important respects. The concrete issue concerns the extent to which they would be willing to continue working beyond the standard age of retirement were jobs to be more flexible in terms of work hours than is currently the case. One hint that this might be quantitatively significant is that part-time options are relatively common in post-career bridge jobs (Maestas, 2010, Rupert and Zanella, 2015) or self-employment (Ramnath, Shoven, and Slavov, 2017). The problem in terms of identification is that there is no obvious behavioral imprint of frustrated desires. Ameriks et al., 2020, introduce an approach to identifying forces on the side of labor supply using SSQs. The corresponding survey instruments directly control for job opportunities in hypothetical situations, which identifies willingness to work independent from what workers expect to find available in the actual labor market. The key finding is that a great many older individuals would work longer, especially if schedules were flexible. Even those who are long retired have strong willingness to work, especially in a job with a flexible schedule.

\subsection{The Evolution of Theory-Based Survey Design}

Those who design survey instruments to elicit beliefs and preferences for estimation of life-cycle models face profound challenges that call for dedicated research. One goal of this paper is to elevate the role of design. I view improvements in instrument design as among the most important yet underappreciated research 
achievements of the modern era of life-cycle research.

Some of the design challenges are universal. These include improving comprehensibility and lowering respondent burden, overcoming the non-intuitive nature of many model constructs, minimizing demand effects, and ridding designs of susceptibility to framing effects and status quo bias to the extent possible. There is also an essentially universal need to strike a balance between comprehensibility and precision. For words, short is good.

The design of probabilistic survey questions illustrates many of the challenges. If one could take for granted probabilistic literacy in respondents, then the ideal questions e.g. about future income, would elicit as many points as space constraints allow on the cumulative distribution. In practice, Dominitz and Manski first elicited maximum and minimum values, essentially to allow the points on the cumulative to be well-placed. This raises the need later to map the words maximum and minimum to percentiles in the cumulative, typically $5 \%$ and $95 \%$. Another challenge in designing the corresponding questions is to ensure that the folk notion of likelihood can be accurately translated into a numerical probability scale. Such a translation cannot be taken for granted. In an ingenious effort to capture folk ideas in a quantitive manner, Delavande and Rohwedder, 2008, introduced a design in which the range between stated minimum and maximum is visually divided into a number of equally-sized bins, with respondents placing balls into the bins to reflect their belief in how relatively likely are the corresponding ranges. What makes this design compelling is that visual devices may be more intuitive for many than are strictly quantitative questions.

However much one might believe in a design, there is no alternative to implementation to sort out the issues. One factor that has shown up perhaps more than was anticipated is rounding (e.g. Bruine de Bruin and Carman, 2012 Delavande and Manski, 2010, Delavande and Rohwedder, 2008, Kreiner, Lassen, and Leth-Petersen, 2014), with focal answers of $0 \%, 50 \%$, and $100 \%$. Methods to reduce rounding are now being introduced. For example it is standard in the Health and Retirement Study to follow up on a response indicating a 50\% probability with a question that asks whether this response represents a belief that the events in question are roughly equally likely or instead that the respondent does not have a clue. The latter answers are not treated as probabilistic. In a possibly related vein, psychologists have long been worried about how attentive survey respondents are to the questions at hand. One method they use is to design trap questions with an unambiguously correct answer to identify participants who are inattentive (Oppenheimer, Meyvis, and Davidenko, 2009). Yet the design of protocols to handle inattention remains at an early stage.

There are many other examples of economic model objects that have folk understanding that may not match the technical concept in which the survey designer is interested. Psychologists have developed elaborate, detailed, and scripted cognitive interviews that pose open-ended questions of interpretation for such cases (de Bruin et al., 2011). One application of these methods relates to ensuring that questions about inflation are interpreted as referring to a general basket of goods rather than a few personally salient items (Armantier et al., 
2015). A second application is to translate technical SSQs to be as simple and direct as possible, with their presentation broken up into bite-sized chunks. The SSQs in Ameriks et al., 2020 went through a particularly rigorous design process. This included fielding of a pilot survey, follow-up debrief interviews with a subset of participants in the pilot survey, and more. In a survey on cognitive decline, responses to the pilot survey caused a complete reorientation of the research project as outlined in section 6.5 below.

An important issue with intricate questions is to gauge comprehension. For each SSQ, there was a corresponding sequence of comprehension questions designed to verify respondent understanding of the scenarios just prior to requesting the answer. There was also an effort to remove anchoring effects when asking for survey responses relating to division of assets. In such allocative questions, there is no cursor on a horizontal line representing all possible allocations. Respondents must click on the bar to place it, and are asked then to move it: meta-data reveals that they cooperated in this regard. As they move the cursor they directly see the amounts of money that they have allocated to each Arrow security.

However much care one might take, there is no way to remove response error. How best to measure and deal with remaining response errors is a topic of active research. Neter and Waksberg, 1964, study response errors in expenditure data from household interviews. Kimball, Sahm, and Shapiro, 2008, model differences in responses to the same question in different waves of the Health and Retirement Study using the assumption that errors are independent and identically distributed. Efforts are also under way to capture the impact of inattention on the structure of survey errors (e.g. Malone and Lusk, 2018). Gillen, Snowberg, and Yariv, 2019, and Morrison and Taubinsky, 2019, introduce methods for using a battery of obviously related survey questions to reduce elicitation error.

\section{Infrastructure Matters}

With its rapidly increasing integration into the research enterprise, the stage is now set for rapid growth of life-cycle data engineering. In this section I look forward to just such growth relating to better understanding patterns in lifetime income (Guvenen et al., 2015, 2021), including the apparently large impact of job transitions, such as layoffs and quits. I open in section 5.1 by outlining what we know from administrative data and important open questions. I stress the importance of developments in survey infrastructure for the most insightful next steps. In section 5.2 I illustrate the value of recently developed panel data on search behaviors, beliefs about job finding probabilities, and reservation wages, for understanding periods of non-employment. These periods are highly heterogeneous, with some re-entering employment quickly and others being unemployed for extended periods. Recent work makes clear that this reflects very significant individual differences in job finding prospects (Mueller, Spinnewijn, and Topa, 2021). 
To set expectations data in appropriate historical context requires surveys that link with rich administrative data. Just such survey infrastructure has been pioneered in the Danish registries (Eppers et al. 2020, Andersen and LethPetersen, 2021). In sections 5.3 I outline the recently initiated Copenhagen Life Panel which uses this architecture to measure and characterize subjective risks to lifetime income at the individual level. Section 5.4 outlines the value of this architecture in estimating models of the impact on earnings of quits and layoffs over the life-cycle (Menzio, Telyukova, and Visschers, 2016). Wages and employment depend as much on firms as on workers. Section 5.5 concludes by highlighting the potential of joint worker-firm data architectures.

\subsection{Lifetime Income and Job Transitions in Administra- tive Data}

An important factor that has liberated the ever expanding reach of life-cycle models of earnings is the growing availability of rich panel data sets. Guvenen et al., 2015, use U.S. social security records to study earnings dynamics over the life-cycle. They show that income growth rates have long left tails and very high kurtosis. They also find that positive changes for high-income individuals are short-lived, whereas negative ones are very long-lived; the opposite is true for low-income individuals. With regard to inequality, Guvenen et al., 2021, again use social security data to show that, from the cohort that entered the labor market in 1957 to the cohort that entered in 1983, median lifetime earnings of men has declined significantly, while for women it has grown, albeit from a lower base. Inequity has risen for both men and women, but the closing gender gap has to some extent counteracted this.

In estimating stochastic processes for earnings, Guvenen et al. 2015, show that differences in years spent in employment have a large impact on growth rates of earnings. Meghir and Pistaferri, 2011, show that it is important to develop a more granular understanding of these periods of non-employment, in particular distinguishing between moving up the job ladder to a better opportunity versus being laid off (Burdett, 1978). Haltiwanger et al, 2018, show that job-to-job moves reallocate younger workers disproportionately from less productive to more productive firms. Altonji, Smith, and Vidangos, 2013 and Low, Meghir, and Pistaferri, 2010, and Lise, Meghir, and Robin, 2016 model lifetime income taking into account job shifts and movements in and out of unemployment.

Estimating the impact of layoffs on lifetime income is one of the central challenges in labor economics. All empirical studies show these effects to be very significant and often long-lasting. Yet many issues are hard to resolve in standard administrative data. Early work of Akerlof and Yellen, 1985, and Topel, 1990, showed that results based on survey recall of firing events were likely biased by aspects of recall itself, such as a possibly greater ability to recall more salient events. Avoiding subjective recall altogether, Jacobson, Lalonde, and Sullivan, 1993 measure in administrative data the effects of being subject to a mass layoff. They estimate strikingly high long-run effects on earnings (on the 
order of 25\%). These effects are very different by age and job tenure (Ruhm, 1991, Farber, Hall, and Pencavel, 1993, Chan and Stevens, 1999). Seim, 2019, implemented an almost ideal version of this mass firing method using Swedish law that employers must report at least 90 days in advance layoffs of 20 or more workers. Yet mass layoffs turn out to be special: Gathmann, Helm, and Schönberg, 2020, use the Swedish data to show that they differ from other layoffs due to slow recovery of local labor markets. Couch and Placzek, 2010 and Ganong and Noel, 2019, incorporate unemployment insurance records in estimating earnings losses from involuntary job loss, while Andersen et al., 2021 use multiple administratively-based methods in the Danish registry. Revisiting the literature using survey method to identify layoff, Handwerker, and Hildreth, 2009 , combine registry and recall data to estimate layoff effects, albeit in a small sample.

Life-cycle data engineering has much to offer in improving our understanding of lifetime income in general and the impact of layoffs and quits in particular. In section $5.2 \mathrm{I}$ outline research on heterogeneity in periods of non-employment using dedicated survey instruments. In section $5.3 \mathrm{I}$ outline holistic research on heterogeneity in income risk using the combined survey-registry methods available in Denmark. In section 5.4 I outline uses of this same data architecture in measuring the impact of job transitions over the life-cycle.

\subsection{Job Search and Heterogeneity}

As noted above, Guvenen et al., 2015, show that heterogeneity in periods out of the labor force is important for understanding patterns of lifetime income inequality. Some get re-employed almost immediately while others enter longterm unemployment. Broadly speaking, exiting unemployment is more and more unlikely as the spell stretches, What standard observational data do not reveal is the extent to which long-term unemployment reduces a worker's chances of finding a job, due perhaps to skill depreciation, as opposed to less employable workers getting left behind. In modeling these differences, Guvenen et al, 2015, assume that all heterogeneity in this and in other outcomes is due to differences in ex post realizations of a common shock process. In essence, this is due to data constraints that make it impossible to identify ex ante differences. This same method is applied in current heterogeneous agents macro models (Heathcote, Storesletten, and Violante, 2009), again due to data constraints. If one wishes to separate out actual ex ante individual differences from differences in luck, data on beliefs is of clear value.

In the case of unemployment, belief-based research estimating heterogeneity in ex-ante risks during unemployment spells includes Hendren, 2017, Conlon et al., 2018, and Mueller, Spinnewijn, and Topa, 2021. Conlon et al., 2018, use a new nationally representative panel data-set on individuals' labor market expectations and realizations. They find that, while expectations about future job offers are highly predictive of actual outcomes, deviations of ex post realizations from ex ante expectations are often sizable.

In an important advance, Mueller, Spinnewijn, and Topa, 2021, engineer 
panel data on unemployed job seekers' perceptions about their employment prospects together with actual labor market transitions. They use both the Federal Reserve Bank of New York Survey of Consumer Expectations and the Survey of Unemployed Workers in New Jersey, which covers a large sample of unemployment insurance recipients (Krueger and Mueller, 2012). As did Conlon et al., they find that the perceived job finding probabilities significantly and strongly predict actual job finding at the individual level. Their findings are more granular and speak to the very different prospects of the unemployed: ex ante heterogeneity can explain the bulk of the observed decline in job finding as the spell stretches. They find that elicited beliefs are unbiased at the start of the unemployment spell, but that beliefs about re-employment probability decline more slowly that the observational data indicate. As a result the longterm unemployed substantially over-estimate their probability of finding a job. They interpret their findings in a model of beliefs which suggests that a very large part of the observed declined in job finding can be explained by dynamic selection. Job seekers with a high underlying job finding rate tend to be overpessimistic, whereas job seekers with a low job finding rate are overoptimistic. Since illusions about job finding probabilities impact the reservation wage, the over-optimistic beliefs of the long-term unemployed themselves contribute to the observed decline in job finding rates.

\subsection{Income Risk over the Life-Cycle}

The impact of incorrect beliefs on reservation search serves to highlight the importance of research on subjective beliefs. Ex ante subjective risk assessment is the basis for all decisions in the face of uncertainty (Heckman and Vytlacil, $2007 \mathrm{a}, \mathrm{b})$. This is true not only for choice of education and setting of reservation wages, but also for whether and when to take time out of the labor force, how intensively to search, whether to move, what to spend, when to retire, etc. A constant theme of the research on income expectations, from Dominitz and Manski, 1997, through today, is their heterogeneity, both within and between narrowly-defined groups. This raises the importance of designing panel data sets to measure the full range of income risk factors over the course of the life-cycle. To understand the evolution of these measures it is important to link these data with historical data capturing individual demographics, relevant aspects of individual history (including family, geography, etc.) and with continuing measurement along the panel dimension.

Research infrastructure allowing targeted surveys based on sampling from and linking back to administrative data is best-developed in the Danish population registry (Kreiner, Lassen, and Leth-Petersen, 2014, Epper at al., 2020, Andersen and Leth-Petersen, 2021). The Danish administrative registries cover about 5.5 million individuals from the 1980s up until now (data is updated with a 1-2 year lag). They contain complete histories of labour market performance with employer-employee links and with information about earnings, hours, employer, and industry for each job. All public registries are linked to a universal social security number that all Danes are equipped with. This makes 
it possible - for research purposes only - to get detailed information about income and wealth, about family structure, education, hospitalization, GP-visits, the purchase of prescription drugs, and more. In addition to allowing one to set expectations in the larger individual, family, and geographic context, the link with the registry allows for structured sampling, appropriate population re-weighting where needed, and credibility checks. Kreiner, Lassen, and LethPetersen, 2014, confirm the high correlation between survey-reported and actual taxable income. Other Scandinavian countries are now developing this ability to link registry and survey. For example Lindqvist, Östling, and Cesarini, 2020 combine registry data on Swedish lottery winners with survey measures of preferences and psychological states.

One of the central goals of the recently initiated Copenhagen Life Panel is to exploit the registry link to improve understanding of income risk over the life-cycle. In particular, new instruments have been implemented to measure short and medium run income risk contingent on job transitions. Following the path laid out by Dominitz and Manski, 1997, the goal of the new panel is to measure subjective income risk over the life-cycle. The ability the registry allows to match income expectations data with administrative data richly documents how beliefs are informed by past realizations.

The Copenhagen Life Panel introduces new survey instruments engineered to measure subjective expectations of future income, with a particular focus on the impact of quits, layoffs, and job transitions. The main instrument designed for this purpose opens by measuring respondents' current work status (essentially at the start of the year). For those working for pay, measures are elicited of the probability of continuing in this work all year, quitting from this work during the year, and being laid off from this work at some point during the year. This is followed by measurement of probabilistic conditional income expectations using a variant of the balls in bins interface of Delavande and Rohwedder, 2008. In the condition in which the job is kept all year, the question about income is simple and direct, with the feature that it asks both for annual income in the upcoming year and in five years. The instrument is more intricate in the quit and layoff branches since there is interest both in how long the period out of the labor force is expected to last, and in income prospects once back in employment. With regard to time out of the labor force, the question concerns probabilities of working for pay again at a variety of time horizons: 1/3/12/24 months. There is then a probabilistic question about the annual rate of pay when back in work. Again, in addition to the annual pay rate on being hired respondents are asked for predictions about five years out.

The goal of the instrument is to quantify and decompose risk i.e. within-job risk, quits/job-to-job opportunities (upside risk) or lay-offs (down-side risk). In preliminary analysis of the resulting data, heterogeneity in subjective income risk is clear. Particularly striking are cases in which income risk is seen as minimal for the foreseeable future. In retrospect this is not surprising, since there are many positions that have high job stability, particularly in the (large) Danish public sector. Many other patterns already clear to the naked eye are sensible. At the early career stage, subjective uncertainty is very high. Younger 
people also have a higher expected growth rates. Subjective short-term risk is predominantly related to risk of job-loss/layoffs (down-side risk) and quits/jobto-job opportunities (up-side risk). Analysis of patterns in these data and their implications for more aggregate models of life-cycle income risk is ongoing.

\subsection{Job Transitions over the Life-Cycle}

The Copenhagen Life Panel reveals that much subjective income risk is concentrated on possible job switches, both layoffs and quits. This brings us back to the issue of how best to interpret subjective beliefs in a full life-cycle framework. Jacobsen, Lalonde, and Sullivan, 1993 showed greater earnings losses upon job loss for older employees. Carrington, 1993, and Chan and Stevens, 1999, showed in particular the reemployment rates were low in higher age groups. Topel and Ward, 1992 found that younger people change jobs more frequently and often in the process increase their earnings. It has therefore become clear that one needs to consider quits and layoffs in a life-cycle framework. Menzio, Telyukova, and Visschers, 2016, develop a model of directed search over the life-cycle and use it to capture key impacts of age and tenure on job transitions and wages. This type of model is of great value in organizing understanding of different effects of job switches not only by age, but also by job tenure.

There are two related issues that make clear the importance of ex ante risk measures of the form gathered in the Copenhagen Life Panel. The first is the oft-noted importance of ex ante beliefs for all decisions related e.g. to quit decisions and to search strategies (Heckman and Vytlacil, 2007a, 2007b, and Mueller, Spinnewijn, and Topa, 2021). The second is the possibility that those who are fired are not randomly selected, so that using data from realized effects on income suffers from self selection. Solutions have been proposed by Heckman and Vytlacil, 2001, 2007a, 2007b, based on availability of sufficiently strong instruments. Briggs et al., 2021, provide conditions under which surveys that measure subjective probabilities of particular events as well as the distribution of possible effects meet these requirements. By design, the conditional income questions in the Copenhagen Life Panel are of precisely this nature. Because of the contingent question structure these surveys reveal how the fear of job loss impacts behavior even among those who do not actually become unemployed.

A key application of the Copenhagen Life Panel is to estimate models of the impact of quits and layoffs across the life cycle in models of directed search, in this way pulling together the strands in the literature. Currently these models are estimated from administrative data using the assumption of rational expectations. Using subjective data allows researchers to understand whether beliefs align with state-of-the-art search models. It also allows analysis of the extent to which the earnings loss associated with displacement differs between those who lose their job and those who do not lose their job (how important is selection). The ability to link all of these outcomes with registry data is critical in determining groups of relatively homogeneous searchers who have similar market conditions upon looking for new jobs (the same market in the directed search sense). The link to the registry also allows comparison with standard 
administratively based measures of transition effects.

Research of this integrative form involves several steps. The first step is to use the Registry to cluster workers into similar types with the purpose of calling these the markets in the directed search sense. This will be by education, age, industry, etc. In the second step these clusters are used to measure representative beliefs about reemployment and income following layoffs and quits. That delivers parameters for the ex ante belief process about these transitions and hence characterizes ex ante treatment effects over the life-cycle. The next stage is to compare these ex ante estimates with ex post estimates based on realizations alone in the directed search framework. This pinpoints ex ante beliefs that are particularly at odds with inferences from standard administrative data with the imposition of rational expectations. This in turn opens up to study such phenomena as possible over-persistence bias in income expectations (Rozsypal and Schlafmann, 2017). The important work, of course, lies ahead of us.

\subsection{Firms and Workers}

Lifetime wages are known to be strongly impacted by heterogeneity among employers. For example Gregory, 2020, shows that jobs differ in terms of how quickly wages grow with tenure. More generally, paths of wages and employment depend on both workers and firms. This means that infrastructure that pioneers in developing quantitative methods of surveying businesses is of very high research value. Panel surveys of a quantitative nature are of particular value. Altig et al., 2020, outline the Survey of Business Uncertainty which elicits subjective probability distributions from business executives about their own firm outcomes at a one-year look-ahead horizon on a monthly basis. They use their panel to provide first order credibility checks. Likewise Bachmann et al., 2020, initiated in 2013 of the Ifo Business Survey, which is a very prestigious and well established survey of business sentiment. Given its importance and deep history, questions are answered by senior management and there is a high response rate. Both surveys provide first order credibility checks. As expertise in surveying businesses develops, one can see the beginnings of the next major innovation in infrastructure, which will allow for joint surveys of firms and workers linked to rich administrative and registry data. Different view on the future of work and rewards to work skills represents an almost ideal setting for further developing linked worker-firm infrastructures. I view this as a particularly exciting engineering frontier.

Going forward, there is particularly high potential in survey architectures that involve sampling firms and their workers simultaneously. Again, such architectures are possible in the Danish population registries. There are many key questions that this may allow to be addressed in relation both to prediction (using supply and demand principles) and to development of the skills that are are rewarded now and in future in terms of earnings. I pick this up again in section 7.3. 


\section{Information Treatments and Policy-Based Data Engineering}

Designing methods to better communicate decision-relevant information is becoming an essential aspect of policy design. In the age of information overload, communicating policy change effectively is best seen as part and parcel of policy itself. In section $6.1 \mathrm{I}$ outline information treatments in the field which have identified many settings in which there is widespread misinformation that can be partially corrected by targeted information treatments. The goal of policy-based data engineering is to understand the channels through which such information treatments operate, thereby to guide their design in welfare-enhancing directions. Since information treatments are believed to operate in large part by impacting knowledge and beliefs, survey-based information treatments are increasingly being implemented to directly gauge these, as outlined in section 6.2. The next two subsections deal with integration of policy-based data engineering into applied research. Section 6.3 focuses on communicating future changes in social security policy, which raises important new issues in relation to credibility. In section $6.4 \mathrm{I}$ outline possible methods of communication to reduce the harmful financial consequences of late-in-life cognitive decline. In section 6.5 I outline ongoing research adopting methods of information theoretic data engineering to welfare rank information treatments.

\subsection{Information Treatments in the Field}

While textbook treatments of public finance model taxes and benefits as fully understood by the population at large, research over the past few decades has made clear that this is far from true. In an early example, De Bartolome, 1995, identified widespread misunderstanding of the distinction between marginal and average income tax rates, which results in highly distorted incentives and calls into question standard theories of optimal taxation that are based on fine tuned incentive effects associated with non-linear taxes. Recent research has expanded on this theme, with Rees-Jones and Taubinsky, 2019, studying the use of simple heuristics to smooth out the actual income tax schedule, and Stantcheva, 2020 showing that political affiliation impacts beliefs about the income tax schedule, with left-wing respondents generally believing income tax rates are lower and less progressive than right-wing respondents.

In recent years findings about misunderstanding of policy have proliferated. One prominent setting relates to the availability of the earned income tax credit in the U.S. Currie stressed lack of understanding of eligibility conditions in writing on "The Invisible Safety Net". Chetty and Saez, 2013, performed an information treatment in which they confirmed that such misunderstanding was prevalent and found ways to change comprehension and increase the rate of uptake. Feldman, Katuščák, and Kawano, 2016, likewise studied taxpayer confusion around the child tax credit and methods for reducing it. Lack of comprehension of local rates of sales tax and whether or not they are included in 
stated price is revealed by the fact that demand falls when they are added to the sticker price and this is clearly conveyed (Chetty, Looney, and Kroft, 2009).

There are many issues of concern to policy makers that are not directly about the tax system in which analogous lack of comprehension has been established and in which corresponding information treatments have major effects. For example Bhargava, Loewenstein, and Sydnor, 2017, find that many participants in company health care plans choose dominated options. They identify that this has an informational basis by running an experiment in which the frame is varied. Specifically, they introduce a high-clarity condition in which subjects are given a plain-language description of plan deductibles, such as: "You pay the first $\$ 500$, then the plan covers remaining expenses." They find that in comparison with a condition in which subjects faced the same descriptions as employees did in the field, the fraction of subjects choosing dominated options fell from $48 \%$ to $18 \%$. Related information treatments impact awareness in myriad other settings, from raising the apparent priority of high quality schooling when academic quality is highlighted (Hastings and Weinstein, 2008, Hoxby and Turner, 2015), to changing patterns of energy use with appropriate messaging (Allcott and Taubinsky, 2015), to raising the productivity of experienced seaweed farmers when scientific information on the determinants of productivity is more clearly presented (Hanna, Mullainathan, and Schwartzstein, 2014).

\subsection{Survey-Based Information Treatments and Updating}

While the results of early information treatments have the obvious implication that information prior to the communication was imperfect and that communication improved this to some degree, they have little to say about general principles that underlie prior ignorance and the extent of learning from communication. In large part this is due to the familiar belief/preference identification problem: behavioral change provides only a very limited window into changes in beliefs. There is by now a rich vein of work that goes beyond this using survey instruments to elicit beliefs before and after treatment. One approach has been to rely on randomized information provision.

Information treatments in general and survey-based information treatments in particular are thoroughly surveyed in Haaland, Roth, and Wohlfart, 2021. There are a great many areas of application. Delavande, 2008, for example, studies how women update their expectations about the effectiveness of contraception methods based on different presentations of the same information. Information treatments and their impact on beliefs are of particular importance in macroeconomics, given the centrality of inflation expectations for the design of monetary policy (Armantier et al., 2015, 2016, Cavallo, Cruces, and PerezTruglia, 2017, Coibion, Gorodnichenko, and Kamdar, 2018, Coibion et al., 2019, Coibion, Gorodnichenko, and Ropele, 2020, Armona, Fuster, and Zafar 2019 and Afrouzi and Yang, 2021). Expectations of both households and firms have been elicited in this manner. The corresponding information treatments operate in general by providing objective information on past inflation to a randomly chosen subset of subjects. There are by now many designs, some involving repeat 
treatment, with an increasing stress on linking to actual decisions. An important open question involves better understanding why respondents appear to have such limited awareness of historical inflation. Afrouzi and Yang, 2021, use a cross country comparison of the effects of an information treatment to motivate a rational inattention model that, together with the actual historical differences in inflationary history, helps explain the observed differences.

One significant challenge in the literature is how precisely to measure the updating induced by the information treatment. Given that asking the same question about expectations twice would likely result in some form of anchoring, a variety of methods have been used that either involve changing the question in some manner, leaving a gap in time between questions, or comparing beliefs across treated and untreated. These challenges and the responses to them are again well treated in Haaland, Roth, and Wohlfart, 2021. Among the most ambitious in terms of measurement of updating is Roth and Wohlfart, 2020. They elicit beliefs about the likelihood of a recession and formally estimate a full model of Bayesian updating based on the information treatment: many prior models focus only on the change in expected value. In the life-cycle context Wiswall and Zafar, 2015a,b use sequential surveys to understand how provision of objective information on returns to schooling alters beliefs. They study the determinants of college major choice using an experimentally generated panel of beliefs, obtained by providing students with information on the true population distribution of various major-specific characteristics. They find that students revise their beliefs in a reasonable manner in response to the information.

\subsection{Communicating Social Security Reform}

Announcing in advance future changes in policy allows those who will be affected to be better prepared. An important case in point concerns adjustments to social security. Policies that delay social security eligibility and benefits are at the top of the agenda and are being implemented around the world (BörschSupan and Coile, 2018, Coile, Milligan, and Wise, 2020). These policies are typically decided many years before they directly affect those of working age so as to allow them to prepare and adjust retirement plans, future earned income, spending and savings. Yet recent evidence suggest that people associate a high degree of uncertainty to such policies. Ciani et al., 2019, elicit beliefs about the probability of future social security reform using cross-country data. They find a significant divergence between announcements and beliefs. This might either be because the public at large does not internalize a credible announcement, or because they find such announcements incredible. Whatever the reason, if such announcements do little to change beliefs, they are unlikely to help those in the working years become better prepared for the policies that eventuate.

Caplin, Leth-Petersen, Lee, and Saeverud, 2021, use survey-based expectations instruments to quantify the success of past communication of a staggered Danish social security claiming age reform. This policy change was announced in 2006 and changed the social security eligibility age from 65 to being based on longevity prospects according to life tables. A table was produced indicating 
eligibility age based on then current, hence provisional, projections of longevity at the time of policy announcement: no changes have since been announced. The implication is that people from recent birth cohorts can expect to become eligible at a later age than people from early cohorts. The intention of the reform is to change the statutory eligibility age more for recent birth cohorts than for earlier birth cohorts, largely in line with anticipated increases in life expectancy.

The heart of the survey involve instruments designed to measure probabilistic beliefs about social security claiming age. These include a randomized information treatment in which half of the sample is shown the table specifying the projected social security eligibility age as published in 2006, which has since become statutory for those of ages 50 and above. The first finding is that, as in other countries, there is a significant difference between policy announced eligibility age and what current workers believe. Younger workers in particular expect to become eligible for social security earlier than the published table indicates. There is also high subjective dispersion. Workers are aware that they do not know, with younger workers in particular highly uncertain.

By itself, the finding of a large gap that is higher for younger workers might either reflect a pure failure to internalize the published table, a pure problem of credibility since the published table was provisional, or some mix. What reveals the former effect to be significant is that the information treatment both reduces the gap with table age and reduces the variance of beliefs. Yet updating is far from complete and a significant gap remains particularly for those who are many years away from the table-based statutory eligibility age. Given the simplicity of the information treatment, one plausible interpretation is that people with many years until becoming eligible find the policy announcement less credible and believe that it might change.

The survey also elicits beliefs about the age of expected retirement and find that the information treatment affects beliefs about the age at which the respondents expects to retire. Those who are treated expect to retire later than those who are not. The survey also elicits the sensitivity of retirement age beliefs to variation in the age of social security eligibility. Those who rely more on social security as a source of income in retirement are more retirement sensitive to the social security eligibility age. Consistent with rational inattention, those for whom social security is financially more important have social security eligibility beliefs that are closer to the official social security eligibility table and their beliefs are also more precise. Key findings can be organized in a simple model of prior beliefs and the updating induced by the information treatment.

\subsection{Cognitive Decline, Awareness, and Communication}

With population aging and the shift from defined benefit to defined contribution pensions, older households are becoming more responsible for managing their own finances during their retirement (Poterba, 2014). It is increasingly important for economists to understand how these households currently handle this issue and to examine the room for improvement (Chandra, Coile, and 
Mommaerts, 2020). A major challenge is that cognitive decline may impact the quality of such decisions. For example, estimates suggest that about one-third of Americans 85 years or older (and 9 percent of those 65 years or older) have dementia (Langa et al., 2017) and cognitive decline without dementia is even more common (Plassman et al., 2007). Cognitive decline appears to make older Americans less capable in terms of financial decision making (Agarwal et al., 2009) and vulnerable to financial fraud (DeLiema et al., 2020).

Many may plan to rely on a third party, such as a family member, to take over decisions when cognitive decline has set in. Yet many who have watched loved ones age are struck by their failure to recognize their own decline. Okonkwo et al., 2008, and Nicholas et al, 2021, present evidence of deterioration in financial skills and increasing financial mistakes, such as missing payments, before a dementia diagnosis. Taking this logic one step further, one might ask how many older wealth-holders are aware both that they might in future decline and that they might not recognize this in time.

Recent research of Ameriks et al., 2021, is designed to shed light on these issues: how many older wealth-holders have a reliable agent and how many are concerned about the timing of their likely transfer of control? The focus of the research was influenced by a pilot survey. Most respondents in a pilot survey were confident in the ability of a trustworthy agent to make good financial decisions on their behalf. On the flip side many appeared concerned about their own future behavior and the possibility that they might fail to transfer control at the right time.

The main survey was designed to quantify concerns about both the quality of an available agent and about the timing of the transfer of control. Responses indicate that, notwithstanding the high quality of the agent, most respondents do not want to transfer control immediately at the onset of decline, but only once it has progressed to a certain limited extent. At the same time, many respondents worry about delaying transfer of control beyond the ex ante optimal time. For those who so worry, SSQs indicate a high willingness to pay for services that would guarantee optimal timing of the transfer.

Policy possibilities are much in need of research. Some possibilities involve financial institutions flagging agreed transactions as prompting an interaction to check that there is no fraud. In addition to obvious cases of wiring massive amounts of funds to previously unknown parties, there may be other cases that would warrant at least a check-in. A related issue is what to do if there are indeed good reasons to worry: might it be time to inform a loved one, and might this too be agreed ahead of time? Would there be any role of agreed checks on cognition? Going back earlier in time, surely it would be worthwhile to communicate our increasing knowledge of the rich life course choices that can impact the path of decline (Rohwedder and Willis, 2010, Langa and Cutler, 2015). Going forward it is important to sharpen these as research questions based on well-developed models supported by correspondingly engineered measurement. 


\subsection{Information Treatments and Welfare}

Welfare is a key goal of policy, even in cases in which behavioral limitations and imperfect information are in evidence. One method to judge improved information derives from measuring priors and posteriors. To give an obvious example, one medical diagnosis is more accurate than another if it reveals all conditions with greater accuracy. Yet in many applications one must make welfare judgements based on changes in behavior rather than in beliefs, as in Bernheim and Rangel, 2009.

Caplin and Martin, 2021, address welfare questions adopting the perspective of an econometrician who wants to compare different ways of presenting the facts based on how valuable that information is for decision-makers. They use the approach in information-theoretic data engineering, which involves an econometrician knowing only the actions taken, and nothing else about the subjective experiment (either the signal structure or the signal realizations). With this information alone, the econometrician might want to determine whether one description of fees lead to better health plan choices made than a different description of the fees, as in Bhargava, Loewenestein, and Snydor, 2017. When the decision-maker's utility function is known, answering this question is easy because the econometrician can directly calculate expected utility using the probability of each action and state. The open question is whether the econometrician can rank experiments without knowing the decision-maker's utility function.

The key is for the econometrician to use choices under the two frames to make inferences about what the experiment might have been for each set of decisions, and use this in turn to restrict the set of utility functions. Data generated by one frame welfare dominates that from another if for every utility function consistent with the data, every experiment consistent with the data in that frame has a higher value of information than every experiment consistent with the latter. In essence, this condition can be satisfied if the data rule out enough utility functions. Caplin and Martin, 2021, show that the NIAS inequalities have a clean geometric structure in the space of outcome lotteries. They build on this structure to produce a necessary and sufficient condition for such welfare domination. The condition is simple to check. Corresponding methods can account for net welfare. There is much to be done joining these theoretical advances with application.

\section{Next Steps}

In this section I present a broader perspective on data engineering as a research process and point to important paths forward. In section 7.1 I specify the information-theoretic data engineering process in the general language of identification. This process operationalizes theoretical constructs which have not made it to the mainstream of applied research. I outline important next steps in this theory-led process. In section $7.2 \mathrm{I}$ outline a distinct process of 
measurement-led engineering, of which life-cycle data engineering is the paradigm case. Section 7.3 illustrates the co-evolution of theory-led and measurement-led engineering as the research process advances. Section 7.4 focuses on the history of information-theoretic and life-cycle data engineering. Thomas Edison and Oscar Wilde both regarded discontent as the first necessity of progress. The long trial-and-error history of economic data engineering reveals this in stark form. Several of the "errors" on which I focus are drawn from my personal research history, with due apologies to co-authors.

\subsection{Theory-Led Data Engineering}

There are three steps in the ideal theory-led engineering process, as exemplified in section 2 in the paradigm case of information-theoretic data engineering.

The first step is to identify an important conceptual and practical limitation of a specified standard modeling and measurement framework $\left(M^{S}, D^{S}, f^{S}\right)$. In the case of information-theoretic data engineering the model class comprises deterministic utility maximization and the data comes in the form of deterministic choice data as conceptualized by Samuelson, 1938. Model and data are well matched: the utility function can in principle be recovered from rich enough such choice data, and the model is testable. The spur to further innovation is discomfort with the maintained assumption that information is complete.

The second step is to introduce a new standard modeling and measurement framework $\left(M^{N S}, D^{N S}, f^{N S}\right)$, ideally nesting the standard one, in which the new standard model is ideally well-identified, so that

$$
f^{N S}: M^{N S} \longrightarrow D^{N S}
$$

is $1-1$, and testable, with $f^{N S}\left(M^{N S}\right)$ a strict subset of $D^{N S}$. In the case of information-theoretic data engineering, the new standard models are the Blackwell model of experimentation and rational inattention theory, and the new standard data set proposed in section 2 is SDSC.

The third step is to implement the corresponding measurements and conduct empirical analyses. Progress in this direction in the case of information-theoretic data engineering is outlined in section 3.

While I have focused in the body of the paper on the example of informationtheoretic data engineering, the work of Block and Marschak, 1959, set an inspiring precedent. As in the information-theoretic case, they took as their standard modeling and measurement framework $\left(M^{S}, D^{S}, f^{S}\right)$ the classical theory of utility maximization and deterministic choice data. The specific conceptual limit on which they focused was the need the theory imposes to interpret any stochasticity in choice as establishing indifference. They then formalized introduction into the economic canon of stochastic choice data and the random utility model. While they showed that their model is in principle identified and testable, the procedure is too demanding of data in its unconstrained form for practical purposes. The key breakthrough in implementation came substantially later in the form of the econometric work of McFadden, 1974 on the logit model, with 
important recent advances by Apesteguia and Ballester, 2018. McFadden's pioneering work follows the standard econometric approach of finding a workable restricted model class $M_{R}^{N S} \subset M^{N S}$ such that

$$
f^{N S}: M_{R}^{N S} \longrightarrow D^{N S} \text {. }
$$

is $1-1$.

Ironically the interpretation of measured randomness in applied work relates to unobserved heterogeneity in preferences at the market level rather than imperfect discrimination. The identifying assumption is that all consumers are perfectly informed (the consideration set model of Manzini and Mariotti, 2014, is a notable exception). This is also standard in market-level applications of discrete choice theory (e.g. Berry, Levinson, and Pakes, 1995, and Roth and Sotomayor, 1992). As indicated in section 2, this interpretation is a far cry from what Block and Marschak had in mind. Extending random utility theory in an information theoretic direction is a high priority going forward.

The main reason for providing an abstract statement of the methods of theory-led engineering is to make clear the many other important roads forward. The abstract statement makes no explicit mention of preferences or beliefs (or economics for that matter). There are many other important models of behavior to posit as the new standard modeling framework $M^{N S}$ and each creates opportunity and need for dedicated new forms of theory-led data engineering. The key in each case is to define appropriate new standard observations $D^{N S}$ and thereby to construct the corresponding mapping $f^{N S}$.

One promising path forward involves allowing for interactions between beliefs and preferences, as in the model of preferences over the temporal resolution of uncertainty due to Kreps and Porteus, 1978. Masatlioglu, Orhun, and Raymond, 2017, design experimental procedures to identify such preferences directly. This relates to models of psychological states that induce such preferences, such as anxiety or surprise (Caplin and Leahy, 2001). The research of Kang and Camerer, 2018, on clock games illustrates possible paths forward in terms of physiological measures of anxiety, again drawing strongly on the psychological tradition. Models of ambiguity attitudes are also due their time in the engineering spotlight. There are experimental measures and survey measures that are under active exploration (Bachmann et al. 2020). Interestingly, there is a link between ambiguity aversion and preferences over the resolution of uncertainty (e.g. Abdellaoui, Klibanoff, and Placido, 2015).

In addition to economic models, there is great potential in incorporating psychological constructs such as costly control (Musslick and Cohen, 2021). In fact there is a striking convergence of interest in costly mental effort as between economics and psychology (Kahneman, 1973, Camerer and Hogarth, 1999, Kool and Botvinick, 2018, Musslick, Cohen, and Shenhav, 2018). Just as in economics, the most recent developments in psychology are motivated by the search for new principles that might underlie a wide variety of behavioral phenomema. Resource rationality (see e.g. Griffiths, Lieder, and Goodman, 2015, and Lieder and Griffiths, 2020, is particularly tightly linked with rational inattention theory (Ma and Woodford, 2020). Efficient coding theory is increasingly 
making its way into economics. For example Khaw, Li, and Woodford, 2017, apply principles of efficient coding to rationalize high apparent risk aversion in small stakes gambles as resulting from imperfect perception. In all of these cases deliberate data enrichment in the engineering style may be of great value.

\subsection{Measurement-Led Data Engineering}

As for its theory-led cousin, the starting point for measurement-led data engineering is a standard modeling and measurement framework $\left(M^{S}, D^{S}, f^{S}\right)$. The underlying challenge relates to issues of identification, in that the mapping is not 1-1 so that many different models produce the same data. As exemplified by McFadden in the case of random utility theory, the econometric approach is to find a workable restricted model class $M_{R}^{S} \subset M^{S}$ such that $f^{S}: M_{R}^{S} \longrightarrow D^{S}$ is 1-1. By contrast, measurement-led data engineering designs innovative forms of data for purposes of identification.

In the paradigm case of life-cycle data engineering the broad model class is the standard life-cycle model with exponential discounting and with time separable period utility functions over consumption and labor supply allowing for any additional factors under study, such as health states and care services etc. The standard data set could be all levels of period consumption, labor supply, health expenses, etc., as ideally measured. As noted in section 4 it has been standard to impose strong identifying assumptions such as full information rational expectations, ex ante homogeneity, and far more, in wide swathes of the literature. Discomfort with these identifying assumptions is the spur to innovation.

The second step in the measurement-led engineering process involves introduction of a new standard data set $D^{N S}$, with $D^{S}$ a strict subset of $D^{N S}$, that in principle overcomes identification problems so that the standard model class maps directly into the enhanced data space and creates a well-identified and testable model class, with

$$
f^{S / N S}: M^{S} \longrightarrow D^{N S} .
$$

being 1-1, and ideally with $f^{S / N S}\left(M^{S}\right)$ a strict subset of $D^{N S}$. In the case of life-cycle data engineering, these new standard data sets are direct survey instruments measuring preferences and beliefs, as detailed in sections 4 and 5 . There has been much progress in terms of identification (albeit less so in terms of testability).

The third step in the measurement-led engineering process is to implement the corresponding measurements and conduct empirical analyses. As detailed in sections 4 and 5 this form of data engineering based on custom-designed survey measures of beliefs and preferences is under way in earnest.

In the case of life-cycle data engineering, the rewards to this form of data enrichment are increasingly clear. For example as expectations measurement has mushroomed, so interesting departures from full information rational expectations have come into view. Barberis, Greenwood, Jin, and Shleifer, 2015, 
model over-reliance on extrapolation in predicting future trends. The possibility that this might explain dynamic patterns in markets is leading to a burst of new research incorporating survey-based expectations measures. Fuster, Laibson, and Mendel, 2010, put forward a theory of natural expectations. Glaeser and Nathanson, 2015, develop models of particularly sticky expectations in the housing market, which is in fact subject to medium run persistence. Rozsypal and Schlafmann, 2017, establish likewise that individuals expect trends in past income to continue more than is true in the evidentiary record.

Many important examples of measurement-led data engineering are to be found in experimental economics. A prime example is use of the strategymethod in experimental games. Standard observational data can reveal only what happens on the path of play. By contrast, the strategy method solves for what would have happened had other players chosen differently. Contingent reasoning involving such counter-factual play is central to equilibrium analysis. Here there are two particularly valuable next steps. The first is to specify richer theories of play that allow for poorly thought through patterns of contingent play in fitting with cognitive constraints. The second is to design new experimental protocols to study contingent beliefs in strategic models of learning.

From a purely methodological perspective, economic data engineering calls for a form of modeling conservatism. The ideal is to model any proposed new forms of measurement using methods that are relatively time tested, such as those of constrained maximization. That is one reason why it has been important for new measurements to be as close to standard economic observations as possible. This also explains recent research designed to better model survey responses and choices in laboratory experiments that may be less than fully attentive (Plott and Zeiler, 2005, Martin and Muñoz-Rodriguez, 2019, Falk, Neuber, and Strack, 2021).

\subsection{Economic Data Engineering as an Evolutionary Pro- cess}

In the information-theoretic case, key next steps include the need to model and measure the dynamics of learning and subjective awareness, as outlined in section 3 above. As this research advances, there are strong reasons to believe that it will contribute to our better understanding the nature of the skills that contribute to later life success, along lines suggested by Deming, 2021, in relation to the quality of individual decision making, and by Weidmann and Deming, 2020, in relation to social skills and their contribution to teamwork. As all who have worked in collaborative teams know, the process of forming a working team is fraught with challenges. Modeling and measuring the learning process is surely of huge value going forward. The best architecture is joint as between well controlled experiments that can separately isolate skills to the extent possible, and life-cycle surveys implemented e.g. in the Danish population registry, that can identify corresponding effects on the evolution of earned income. An important aspect is to tie this to employers, to examine the extent to which particular firms and industries aid in development of future earning potential. 
In the case of life-cycle data engineering an important next step involves modeling and measuring the possible importance of memories in impacting beliefs. The key to independent interest in this topic is that the mapping of history to memory is far from trivial, with issues of salience particularly important (Bordalo, Gennaioli, and Shleifer, 2021). Recent models of how history informs memory due to da Silveira, Sung, and Woodford, 2020, Bordalo, Gennaioli, and Shleifer, 2017, and Wachter and Kahana, 2019, present intriguing opportunities for data engineering. It is worth noting in this regard the work of Akerlof and Yellen, 1985, on limited recall of past experiences of unemployment. This gave rise to an interesting early literature on salience effects, fading of memories over time, and even telescoping effects in which far back events are recalled as more recent (Topel, 1990). This is an exciting area of research in which information-theoretic and life-cycle based data engineering are highly complementary.

There are hybrid cases of theory-led and measurement-led engineering in which news form of data are of clear theoretical value and the question is precisely which theories they help to identify. Such is the case with choice over choice sets, which was first formally conceptualized by Koopmans, 1962, reflecting his stated belief that typical choices exclude certain options while leaving many others open (e.g. choice of educational program, restaurant, etc.) The value of this data set was expanded on by Kreps, 1979, who used it to capture preference for flexibility. Following this, Dekel, Lipman, and Rustichini, 2001, and Gul and Pesendorfer, 2001 showed how this data can be used to model self-control problems. The very deliberate field design of Toussaert, 2018 implemented the model of Gul and Pesendorfer in the field, as did the survey work of Ameriks et al. 2008. One interesting aspect is that there are also identification problems in this data set. For example De Oliveira et al., 2017, use it to characterize a general model of rational inattention. While the appropriate model might sometimes be clear from context, general methods for separately identifying these diverse theories may be of value.

Other new forms of measurement raise entirely new modeling possibilities involving as yet unrecognized identification problems and corresponding further measurement innovations. Three such examples are biological data that links to behavior (e.g. genetic, hormonal, etc.), textual data of the form that is becoming central in study of political dynamics, and rich data on social networks. Each of these is a massive area in its own right, and there is important work to be done developing corresponding modeling frameworks. From the engineering viewpoint these are again exciting research frontiers.

\subsection{Discontent as a Spur to Progress}

The history of data engineering well illustrates the importance of discontent as a spur to progress. It also illustrates how very challenging it is to identify new forms of data that are closely related to economic theory. In practice, advances that have stuck resulted from long trial-and-error processes.

As noted in section 2, the original proposal for information-theoretic data 
engineering dates back more than sixty years to Block and Marschak, 1959. They were not alone in their discontent with the classical theory of fully informed optimization. Many others have proposed data enrichments to separate out knowledge and preferences. Ericsson and Simon, 1980, for example, introduced verbal protocol analysis to better understand the nature of the search process and its relation to final choice. Likewise concerned with procedure, Payne, Bettman, and Johnson, 1993, introduced data on mouse-clicks to understand information search and choice. That this data can be economically insightful is revealed by such contributions as Johnson et al, 2002, Gabaix, Moloche, and Laibson, 2006, and Geng, 2015. Other search related psychological data include eye tracking and even neural activity. Reutjeska et al., 2011, use eye tracking technology to better understand methods of search and their interaction with choice.

The challenge from an engineering perspective is that no one has effectively captured the words that are spoken, the precise pattern of mouse-click activity, visual search, or neural signals in general models of learning and choice. That is why Block and Marschak stressed the advantage of new measurements being as close as possible to standard choice data.

My personal research history well illustrates both the powerful role of discontent, and the trial-and-error process of data design. The first identification problem that struck home was psychological in nature. What behavior reveals whether rejection of information is due to a love of surprise or the additional worry it might cause (Caplin and Leahy, 2004)? Focusing on inference from observed data, it soon became clear that there is an earlier and more basic problem. What behavior reveals what is and what is not known at point of decision? The path forward that I have outlined in sections 2 and 3 involves using SDSC to tease this out to the extent possible. But before that, Mark Dean, Daniel Martin, and I proposed use of choice process data, which captures provisional choices during the search process, to better identify theories of learning (Campbell, 1978, Caplin and Dean, 2011, and Caplin, Dean, and Martin, 2011). While of value in its own right, there are two particular limitations of this on a stand-alone basis as an ideal form of information-theoretic data engineering. First, it is of most value in a limited class of learning models involving sequential search. In these cases, and only in these cases, can one infer that replacement of one option with another implies a preference for the newly picked one. With other forms of learning, prevarication is likely and is indeed common in applications (e.g. Agranov, Caplin, and Tergiman, 2015). Second, it is more highly artificial than state dependent stochastic choice data and hence unlikely to take such a central place in applied microeconomic research. It was this continued discontent that spurred the further innovations outlined in section 2 .

The form of discontent that spurred life-cycle data engineering derives from entirely different sources. Here professional attitudes dismissive of survey evidence slowed down progress in design, with, as Manski noted pointedly, little empirical justification. Perhaps not surprisingly in this light, it was the psychologist George Katona who played the pivotal role introducing economists to survey methods (Katona, 1960). Under his leadership, survey-based mea- 
sures of consumer sentiment were developed in the late 1940's and ultimately launched as the Consumer Sentiment Index by the University of Michigan, 1960. A step forward in quantification in the context of spending and saving is due to Juster, 1966, who developed a novel survey instrument that associated verbal expressions of likelihood with numerical probabilities to elicit the likelihood of purchasing durable goods such as cars. As one might expect, he found that elicited purchase probabilities were better predictors of subsequent individual purchase behavior than were the traditional yes-no questions on purchase plans. As noted in section 4, Manski was quite explicit in stressing his discontent with the standard identifying assumptions in modeling of future oriented behavior. Finally the field is taking off as warranted.

The trial-and-error process relates not only to the form of data, but the precise nature of the measurements. This is particularly important in the case of life-cycle data engineering in which the mapping between model constructs and survey questions is always up for debate.

The case of measured risk aversion well illustrates this aspect of data engineering. The first such measurements took place in experimental contexts and featured relatively small amounts of money, as in the Holt-Laury scale (Holt and Laury, 2002). Rabin and Thaler, 2001, made the point that showing any degree of risk aversion in such small stakes decisions would yield absurdly high levels of risk aversion in the large. Khaw, Li, and Woodford, 2017, followed this line of logic and made a formal argument that the answers to small stakes risk aversion questions reflect imperfect information due to optimal coding rather than risk aversion per se. To measure risk aversion in the large, Barsky et al., 1997, introduced preference parameter questions that placed enough wealth on the line to significantly alter future consumption possibilities. The pioneering version of this instrument compared a safe status quo job to a switch of job that involved higher expected income but also higher risk. This was critiqued in that the safe option also involves maintaining the status quo job, a potentially significant confound. Subsequent versions insisted that the job was to change in either case, to isolate the income change. But there are other issues to think about, since the question does not control later behavior or directly tie income to spending. There are ongoing efforts to design SSQs that are more specific in these respects and therefore more precisely tied the model construct, which is risk aversion in consumption spending. These questions are more intricate and there are likely respondents who will not pay full attention. In this as in other cases, there is no perfect instrument.

My own survey-based research illustrates again both the trial-and-error process and the evolution over time to be more tightly linked to theoretical constructs. An early paper on the propensity to plan uncovered a robust link between psychologically measured planning propensities and wealth accumulation that appeared not to go through a standard channel such as the discount rate (Ameriks, Caplin, and Leahy, 2003). What limits the reach of these findings is that the survey instrument was not tightly tied to a theory of planning. The challenge this created was ex post interpretation. We were not able to develop a simple model of planning that linked it to low spending. In fact the most nat- 
ural model suggests that planning lowers subjective uncertainty, which should perhaps liberate lower rather than higher levels of precautionary savings. There is much interesting work to be done driving forward in this area, but it may need a substantially richer psychological notion of planning and corresponding innovations in measurement. Be that as it may, the experience with an imperfect match between model and measurement made it ever more important in my own research path to pin down model objects of interest prior to designing surveys. The strategic survey questions outlined in section 4 above were arrived at by an evolution in favor of model-based instruments.

The discontent that characterizes the engineering mindset may be of value even in branches of applied research that employ different empirical methodologies. There may be two related virtues of incorporating more elements of data engineering into field experiments and randomized control trials. The first concerns the ubiquitous challenge of capturing imperfect awareness of the intervention itself. The assumption of full information implicit in interpretations of the results of such experiments and trials is just that: an assumption. To the extent that the trial is so well publicized that all understand it, it will not generalize to the real world setting in which information is imperfect. To the extent that information is imperfect, there is no way to know how the degree of ignorance would be different were the corresponding policy to be instituted and therefore how well the results would generalize. At the very least, it would seem valuable to gather ex ante and ex post beliefs about the intervention, for example using survey instruments. In as much as such questions are posed, they could be posed not only to those who are included in the trial, but to a far broader group not so included. Full modeling of ex ante and ex post treatment effects might allow inference about the generalizability of the results of the trial. The recent work of Briggs et al., 2021, on policy-relevant treatment effects, makes this point formally. It picks up on ideas of Heckman and Vytlacil, 2001 , and proposes methods to identify ex ante treatment effects as relevant to decision making.

\subsection{The Research Enterprise and Social Scientific Progress}

Economic data engineering requires diverse research teams and in many cases significant resources. The history of both information-theoretic and life-cycle data engineering involved economists internalizing and adapting research methods that are psychological in origin. More broadly, many of the most promising paths going forward involve reaching across disciplinary boundaries. The largest and most ambitious engineering projects would be addressed to major societal challenges, such as improving education and health-care, reducing discrimination (see section 3), raising the quality of justice (see section 3), better understanding and reducing lifetime income equality (see section 5), and even reducing environmental pollution (Caplin et al. 2019). These require collaborations that cross not only barriers between the social sciences, but also between the social and natural sciences, data science, and engineering.

It is an open secret that the structure of research institutions creates im- 
pediments to the necessary forms of teamwork. It remains very challenging to support large scale interdisciplinary research enterprises in current institutional structures. To some extent this is starting to change. As Buyalskaya, Gallo, and Camerer, 2021, point out, constraints on academic teamwork are being loosened. In an ideal world this process would accelerate. Economic data engineering could then serve as a central node connecting different academic fields as needed to address social scientific challenges. How to get closer to this ideal is a valid research question in its own right. 


\section{Bibliography}

\section{References}

[1] Abaluck, J., Gruber, J. and Swanson, A., 2018. Prescription drug use under Medicare Part D: A linear model of nonlinear budget sets. Journal of public economics, 164, pp.106-138.

[2] Abdellaoui, M., Klibanoff, P. and Placido, L., 2015. Experiments on compound risk in relation to simple risk and to ambiguity. Management Science, 61(6), pp.1306-1322.

[3] Achtziger, Anja, and Carlos Alos-Ferrer. 2014. "Fast or Rational? A Response-Times Study of Bayesian Updating." Management Science, 60 (4): 923-938.

[4] Afriat, S.N., 1967. The construction of utility functions from expenditure data. International economic review, 8(1), pp.67-77.

[5] Afrouzi, H., and Yang, C. (2021). Selection in Information Acquisition and Monetary Non-Neutrality.

[6] Agarwal, S., Driscoll, J.C., Gabaix, X. and Laibson, D., 2009. The age of reason: Financial decisions over the life cycle and implications for regulation. Brookings Papers on Economic Activity, 2009(2), pp.51-117.

[7] Agranov, Marina, Andrew Caplin, and Chloe Tergiman. 2015. "Naive Play and the Process of Choice in Guessing Game." Journal of the Economic Science Association 1: 1-12.

[8] Akerlof, G.A. and Yellen, J.L., 1985. Unemployment through the Filter of Memory. The Quarterly Journal of Economics, 100(3), pp.747-773.

[9] Allcott, H. and Taubinsky, D., 2015. Evaluating behaviorally motivated policy: Experimental evidence from the lightbulb market. American Economic Review, 105(8), pp.2501-38.

[10] Alós-Ferrer, C., Fehr, E. and Netzer, N., 2021. Time will tell: Recovering preferences when choices are noisy. Journal of Political Economy, 129(6), pp.1828-1877.

[11] Altig, D., Barrero, J.M., Bloom, N., Davis, S.J., Meyer, B. and Parker, N., 2020. Surveying business uncertainty. Journal of Econometrics.

[12] Altonji, J.G., Smith Jr, A.A. and Vidangos, I., 2013. Modeling earnings dynamics. Econometrica, 81(4), pp.1395-1454.

[13] Ambuehl, Sandro and Ockenfels, Axel and Stewart, Colin. 2018. "Attention and Selection Effects." Rotman School of Management Working Paper No. 3154197. Available at SSRN: https://ssrn.com/abstract=3154197 or http://dx.doi.org/10.2139/ssrn.3154197 
[14] Ameriks, John, Joseph Briggs, Andrew Caplin, Matthew Shapiro, and Christopher Tonetti. 2015. "Long-Term Care Utility and Late in Life Saving." National Bureau of Economic Research, Working Paper 20973.

[15] Ameriks, John, Joseph Briggs, Andrew Caplin, Minjoon Lee, Matthew Shapiro, and Christopher Tonetti. 2020. Older Americans Would Work Longer If Jobs Were Flexible. American Economic Journal: Macroeconomics, 12(1), 174-209, 2020.

[16] Ameriks, John, Andrew Caplin, Steven Laufer, and Stijn Van Niewerburgh. 2011. "The Joy of Giving or Assisted Living: Using Strategic Surveys to separate Bequest and Precautionary Motives." Journal of Finance 66.2: $519-561$.

[17] Ameriks, John, Andrew Caplin, and John Leahy. 2003. Wealth Accumulation and the Propensity to Plan," with John Ameriks and John Leahy, Quarterly Journal of Economics, 118, 1007-1047, 2003.

[18] Ameriks, John, Andrew Caplin, John Leahy, and T. Tyler. 2007. Measuring Self-Control Problems. American Economic Review, vol.97, 966-972, 2007.

[19] Ameriks, J. Andrew Caplin, Minjoon Lee, Matthew D. Shapiro, and Christopher Tonetti. 2021. Cognitive Decline, Limited Awareness, Imperfect Agency, and Financial Well-being.

[20] Andersen, H.Y. and Leth-Petersen, S., 2021. Housing wealth or collateral: How home value shocks drive home equity extraction and spending. Journal of the European Economic Association, 19(1), pp.403-440.

[21] Andersen, A.L., Jensen, A.S., Johannesen, N., Kreiner, C.T., LethPetersen, S. and Sheridan, A., 2021. How Do Households Respond to Job Loss? Lessons from Multiple High-Frequency Data Sets.

[22] Angeletos, G.M. and Sastry, K., 2019. Inattentive economies (No. w26413). National Bureau of Economic Research.

[23] Angrist, Joshua D., and Jörn-Steffen Pischke. 2008. Mostly harmless econometrics: An empiricist's companion. Princeton University Press.

[24] Angrist, Joshua D., Guido W. Imbens, and Donald B. Rubin. 1996. "Identification of causal effects using instrumental variables." Journal of the American statistical Association 91, no. 434: 444-455.

[25] Apesteguia, J. and Ballester, M.A., 2018. Monotone stochastic choice models: The case of risk and time preferences. Journal of Political Economy, 126(1), pp.74-106.

[26] Archsmith, J.E., Heyes, A., Neidell, M.J. and Sampat, B.N., 2021. The Dynamics of Inattention in the (Baseball) Field (No. w28922). National Bureau of Economic Research. 
[27] Arcidiacono, P., Hotz, V.J. and Kang, S., 2012. Modeling college major choices using elicited measures of expectations and counterfactuals. Journal of Econometrics, 166(1), pp.3-16.

[28] Arcidiacono, Peter, V. Joseph Hotz, Arnaud Maurel, and Teresa Romano. 2014. "Recovering ex ante returns and preferences for occupations using subjective expectations data." No. w20626. National Bureau of Economic Research.

[29] Armantier, O., Bruine de Bruin, W., Topa, G., Van Der Klaauw, W. and Zafar, B., 2015. Inflation expectations and behavior: Do survey respondents act on their beliefs?

[30] Armantier, O., Nelson, S., Topa, G., Van der Klaauw, W. and Zafar, B., 2016. The price is right: Updating inflation expectations in a randomized price information experiment. Review of Economics and Statistics, 98(3), pp.503-523.. International Economic Review, 56(2), pp.505-536.

[31] Armona, L., Fuster, A. and Zafar, B., 2019. Home price expectations and behaviour: Evidence from a randomized information experiment. The Review of Economic Studies, 86(4), pp.1371-1410.

[32] Arrow, K.J., 1972. Some mathematical models of race discrimination in the labor market. Racial discrimination in economic life, pp.187-204.

[33] Attanasio, O.P. and Weber, G., 2010. Consumption and saving: models of intertemporal allocation and their implications for public policy. Journal of Economic literature, 48(3), pp.693-751.

[34] Avoyan, A. and Romagnoli, G., 2019. Paying for Inattention. Available at SSRN 3427147.

[35] Bachmann, R., Carstensen, K., Lautenbacher, S. and Schneider, M., 2020. Uncertainty is more than risk-survey evidence on knightian and bayesian firms (pp. 1-35). Technical Report.

[36] Bailey, Michael, Ruiqing Cao, Theresa Kuchler, and Johannes Stroebel. Forthcoming. "The Economic Effects of Social Networks: Evidence from the Housing Market". Journal of Political Economy

[37] Barberis, Nicholas, Robin Greenwood, Lawrence Jin, and Andrei Shleifer. 2015. "X-CAPM: An extrapolative capital asset pricing model." Journal of Financial Economics 115, no. 1: 1-24.

[38] Barsky, Robert B., F. Thomas Juster, Miles S. Kimball, and Matthew D. Shapiro. 1997. "Preference parameters and behavioral heterogeneity: An experimental approach in the health and retirement study." Quarterly Journal of Economics 112.2: 537-579. 
[39] Bartoš, V., Bauer, M., Chytilová, J. and Matějka, F., 2016. Attention discrimination: Theory and field experiments with monitoring information acquisition. American Economic Review, 106(6), pp.1437-75.

[40] Becker, Gary. 1957. The Economics of Discrimination, Chicago: University of Chicago Press.

[41] Ben-Akiva, M., McFadden, D. and Train, K., 2015. Foundations of stated preference elicitation. University of California, Berkeley. http://eml. berkeley. edu/train/foundations. pdf.

[42] Benjamin, D.J., Heffetz, O., Kimball, M.S. and Rees-Jones, A., 2012. What do you think would make you happier? What do you think you would choose?. American Economic Review, 102(5), pp.2083-2110.

[43] Benoît, J.P. and Dubra, J., 2011. Apparent overconfidence. Econometrica, 79(5), pp.1591-1625.

[44] Berinsky, Adam J., Michele Margolis, and Michael Sances. 2014. "Separating the Shirkers from the Workers? Making Sure Participants Pay Attention on Internet Surveys." American Journal of Political Science. $58(3): 739-53$.

[45] Bernheim, B. Douglas, and Antonio Rangel. 2009. "Beyond revealed preference: choice-theoretic foundations for behavioral welfare economics." Quarterly Journal of Economics 124, no. 1 (2009): 51-104.

[46] Bernheim, B.D., Bjorkegren, D., Naecker, J. and Rangel, A., 2013. Nonchoice evaluations predict behavioral responses to changes in economic conditions (No. w19269). National Bureau of Economic Research.

[47] Berry, S., Levinsohn, J. and Pakes, A., 1995. Automobile prices in market equilibrium. Econometrica: Journal of the Econometric Society, pp.841890.

[48] Bertrand, M. and Mullainathan, S., 2004. Are Emily and Greg more employable than Lakisha and Jamal? A field experiment on labor market discrimination. American economic review, 94(4), pp.991-1013.

[49] Bessone, P., Rao, G., Schilbach, F., Schofield, H. and Toma, M., 2019. Sleepless in Chennai: The consequences of increasing sleep among the urban poor. mimeo.

[50] Bhargava, S. and Manoli, D., 2015. Psychological frictions and the incomplete take-up of social benefits: Evidence from an IRS field experiment. American Economic Review, 105(11), pp.3489-3529.

[51] Bhargava, S., Loewenstein, G. and Sydnor, J., 2017. Choose to lose: Health plan choices from a menu with dominated option. The Quarterly Journal of Economics, 132(3), pp.1319-1372. 
[52] Bhattacharya, V. and Howard, G., 2021. Rational Inattention in the Infield. American Economic Journal: Microeconomics.

[53] Blackwell, D., 1953. Equivalent comparisons of experiments. The annals of mathematical statistics, pp.265-272.

[54] Blass, A.A., Lach, S. and Manski, C.F., 2010. Using elicited choice probabilities to estimate random utility models: Preferences for electricity reliability. International Economic Review, 51(2), pp.421-440.

[55] Block, Henry David, and Jacob Marschak. Random orderings and stochastic theories of response." No. 66. Cowles Foundation for Research in Economics, Yale University, 1959.

[56] Bloedel, A.W. and Zhong, W., 2020. The cost of optimally-acquired information. Unpublished Manuscript, November.

[57] Bordalo, P., Gennaioli, N. and Shleifer, A., 2012. Salience theory of choice under risk. The Quarterly journal of economics, 127(3), pp.1243-1285.

[58] Bordalo, P., Gennaioli, N. and Shleifer, A., 2017. Memory, attention, and choice. The Quarterly journal of economics.

[59] Bordalo, P., Gennaioli, N. and Shleifer, A., 2021. Salience (No. w29274). National Bureau of Economic Research.

[60] Börsch-Supan, A.H. and Coile, C., 2018. Social security programs and retirement around the world: reforms and retirement incentives-introduction and summary (No. w25280). National Bureau of Economic Research.

[61] Brier, G.W., 1950. Verification of forecasts expressed in terms of probability. Monthly weather review, 78(1), pp.1-3.

[62] Bronchetti, E.T., Kessler, J.B., Magenheim, E.B., Taubinsky, D. and Zwick, E., 2020. Is Attention Produced Rationally? (No. w27443). National Bureau of Economic Research.

[63] Briggs, J., A. Caplin, S. Leth-Petersen, and C. Tonetti. 2021. Estimating Marginal Treatment Effects with Survey Instruments.

[64] Brown, Z.Y. and Jeon, J., 2019. Endogenous Information Acquisition and Insurance Choice. University of Michigan and Boston University Working Paper.

[65] Brown, J.N. and Rosen, H.S., 1982. On the estimation of structural hedonic price models. Econometrica: Journal of the Econometric Society, pp.765-768.

[66] Buyalskaya, A., Gallo, M. and Camerer, C.F., 2021. The golden age of social science. Proceedings of the National Academy of Sciences, 118(5). 
[67] Bruine de Bruin, W. and Carman, K.G., 2012. Measuring risk perceptions: what does the excessive use of 50

[68] Burdett, K., 1978. A theory of employee job search and quit rates. The American Economic Review, 68(1), pp.212-220.

[69] Callaway, F., Rangel, A. and Griffiths, T.L., 2020. Fixation patterns in simple choice are consistent with optimal use of cognitive resources. PsyArXiv, 10.

[70] Camerer, C.F. and Hogarth, R.M., 1999. The effects of financial incentives in experiments: A review and capital-labor-production framework. Journal of risk and uncertainty, 19(1), pp.7-42.

[71] Cameron, C.M. and Kornhauser, L.A., 2006. Appeals mechanisms, litigant selection, and the structure of judicial hierarchies. Institutional Games and the US Supreme Court, 173, p.204.

[72] Campbell, D.E., 1978. Realization of choice functions. Econometrica: Journal of the Econometric Society, pp.171-180.

[73] Campbell, J.Y., 2016. Restoring rational choice: The challenge of consumer financial regulation. American Economic Review, 106(5), pp.1-30.

[74] Cao, X. and Zhang, J., 2021. Preference learning and demand forecast. Marketing Science, 40(1), pp.62-79.

[75] Caplin, A., Csaba, D., Leahy, J. and Nov, O., 2020. Rational inattention, competitive supply, and psychometrics. The Quarterly Journal of Economics, 135(3), pp.1681-1724.

[76] Caplin, Andrew, and Mark Dean. 2011. "Search, Choice, and Revealed Preference." Theoretical Economics, Volume 6, Issue 1, pages 19-48.

[77] Caplin, A. and Dean, M., 2013. Behavioral implications of rational inattention with shannon entropy (No. w19318). National Bureau of Economic Research.

[78] Caplin, Andrew, and Mark Dean. 2015. "Revealed Preference, Rational Inattention, and Costly Information Acquisition." American Economic Review, 105(7): 2183-2203.

[79] Caplin, Andrew, Mark Dean and John Leahy. 2019. Rational Inattention, Optimal Consideration Sets, and Stochastic Choice". Review of Economic Studies, Volume 86, Issue 3, Pages 1061-1094.

[80] Caplin, Andrew, Mark Dean and John Leahy. 2021. Rationally Inattentive Behavior: Characterizing and Generalizing Shannon Entropy. Journal of Political Economy, forthcoming. 
[81] Caplin, Andrew, Mark Dean, and Daniel Martin. 2011. "Search and Satisficing." American Economic Review, 101: 2899-2922.

[82] Caplin, Andrew, Masoud Ghandehari, Chris Lim, Paul Glimcher, and George Thurston. 2019. Advancing environmental exposure assessment science to benefit society." With . Nature Communications 10, no. 1: 111.

[83] Caplin, A., Gomberg, A. and Sadka, J., 2021. Measuring, Modeling, and Minimizing Judicial Errors.

[84] Caplin, Andrew and John Leahy. 2004. The Supply of Information by a Concerned Expert. Economic Journal, 487-505.

[85] Caplin, Andrew and John Leahy. 2001. Psychological Expected Utility Theory and Anticipatory Feelings. Quarterly Journal of Economics, 5580 .

[86] Caplin, A., Leahy, J. and Matějka, F., 2015. Social learning and selective attention (No. w21001). National Bureau of Economic Research.

[87] Caplin, Andrew. Minjoon Lee, Soren Leth-Petersen, Johan Saeverud, and Matthew Shapiro. 2021. Impacts on Productivity of Job-Specific and General Experience: The Business Perspective. Mimeo.

[88] Caplin, A,. S. Leth-Petersen, E.Lee, and J. Saeverud. 2021. Communicating Social Security Reform.

[89] Caplin, Andrew, and Daniel Martin. 2105. "A Testable Theory of Imperfect Perception." Economic Journal 125.582: 184-202.

[90] Caplin, Andrew, and Daniel Martin. 2016. "The Dual-Process Drift Diffusion Model: Evidence from Response Times." Economic Inquiry. 12741282

[91] Caplin, Andrew, and Daniel Martin. 2021. Comparison of Decisions under Unknown Experiments," with Daniel Martin. Forthcoming Journal of Political Economy.

[92] Carrasco, M., 2011. Visual attention: The past 25 years. Vision research, 51(13), pp.1484-1525.

[93] Carrington, W.J., 1993. Wage losses for displaced workers: Is it really the firm that matters?. Journal of Human Resources, pp.435-462.

[94] Carroll, C.D., 2001. Death to the log-linearized consumption Euler equation!(And very poor health to the second-order approximation). The BE Journal of Macroeconomics, 1(1).

[95] Carvalho, L. and Silverman, D., 2019. Complexity and sophistication (No. w26036). National Bureau of Economic Research. 
[96] Cavallo, A., Cruces, G. and Perez-Truglia, R., 2017. Inflation expectations, learning, and supermarket prices: Evidence from survey experiments. American Economic Journal: Macroeconomics, 9(3), pp.1-35.

[97] Chabris, Christopher, Carrie Morris, Dmitry Taubinsky, David Laibson, and Jonathon Schuldt. 2009. "The Allocation of Time in DecisionMaking." Journal of the European Economic Association, 7: 628-637.

[98] Chan, S. and Stevens, A.H., 1999. Employment and retirement following a late-career job loss. American Economic Review, 89(2), pp.211-216.

[99] Chandra, A., Coile, C. and Mommaerts, C., 2020. What Can Economics Say About Alzheimer's Disease? (No. w27760). National Bureau of Economic Research.

[100] Chetty, Raj, Adam Looney, and Kory Kroft. 2009. "Salience and Taxation: Theory and Evidence." American Economic Review, 99, 1145-1177.

[101] Chetty, R. and Saez, E., 2013. Teaching the tax code: Earnings responses to an experiment with EITC recipients. American Economic Journal: Applied Economics, 5(1), pp.1-31.

[102] Ciani, E., Delavande, A., Etheridge, B. and Francesconi, M., 2019. Policy Uncertainty and Information Flows: Evidence from Pension Reform Expectations.

[103] Coibion, O., Georgarakos, D., Gorodnichenko, Y. and Van Rooij, M., 2019. How does consumption respond to news about inflation? Field evidence from a randomized control trial (No. w26106). National Bureau of Economic Research.

[104] Coibion, O., Gorodnichenko, Y. and Kamdar, R., 2018. The formation of expectations, inflation, and the phillips curve. Journal of Economic Literature, 56(4), pp.1447-91.

[105] Coibion, Olivier, Yuriy Gorodnichenko, and Tiziano Ropele. "Inflation expectations and firm decisions: New causal evidence." The Quarterly Journal of Economics 135.1 (2020): 165-219.

[106] Coile, C.C., Milligan, K. and Wise, D.A. eds., 2020. Social security programs and retirement around the world: working longer. University of Chicago Press.

[107] Conlon, J.J., Pilossoph, L., Wiswall, M. and Zafar, B., 2018. Labor market search with imperfect information and learning (No. w24988). National Bureau of Economic Research.

[108] Couch, K.A. and Placzek, D.W., 2010. Earnings losses of displaced workers revisited. American Economic Review, 100(1), pp.572-89. 
[109] Csaba, D., 2021. Attention elasticities and invariant information costs. arXiv preprint arXiv:2105.07565.

[110] Currie, J.M., 2008. The invisible safety net. Princeton University Press.

[111] Currie, J. and MacLeod, W.B., 2017. Diagnosing expertise: Human capital, decision making, and performance among physicians. Journal of labor economics, 35(1), pp.1-43.

[112] da Silveira, R.A., Sung, Y. and Woodford, M., 2020. Optimally imprecise memory and biased forecasts (No. w28075). National Bureau of Economic Research.

[113] De Bartolome, C.A., 1995. Which tax rate do people use: Average or marginal?. Journal of public Economics, 56(1), pp.79-96.

[114] de Bruin, W.B., Baldassi, M., Figner, B., Fischhoff, B., Fleishman, L., Hardisty, D., Johnson, E., Keren, G., Konnikova, M., Levin, I. and Li, Y., 2011. Framing effects in surveys: How respondents make sense of the questions we ask. Perspectives on Framing, edited by Gideon Keren, pp.303-325.

[115] De Finetti, Bruno. 1965. "Methods for Discriminating Levels of Partial Knowledge Concerning a Test Item." British Journal of Mathematical and Statistical Psychology 18.1: 87-123.

[116] De Nardi, Mariacristina, Eric French, and John Bailey Jones. 2009. "Life expectancy and old age savings." American Economic Review 99.2: 11015.

[117] De Nardi, Mariacristina, Eric French, and John B. Jones. 2010. "Why do the elderly save? The role of medical expenses." Journal of Political Economy 118.1 (2010): 39-75.

[118] De Nardi, Mariacristina, Eric French, and John Bailey Jones. 2016. "Savings after retirement: A survey." Annual Review of Economics 8: 177-204.

[119] De Nardi, Mariacristina, Eric French, John Bailey Jones, and Jeremy McCauley. 2016. "Medical spending of the US elderly." Fiscal Studies 37, no. 3-4: $717-747$.

[120] De Oliveira, Henrique, Tommaso Denti, Maximilian Mihm, and Kemal Ozbek. 2017. "Rationally inattentive preferences and hidden information costs." Theoretical Economics 12, no. 2: 621-654.

[121] Dean, J.T., 2019. Noise, cognitive function, and worker productivity. mimeo.

[122] Dean, Mark, and Nathaniel Neligh. 2016. "Experminental Tests of Rational Inattention." Columbia University Working Paper. 
[123] Dekel, E., Lipman, B.L. and Rustichini, A., 2001. Representing preferences with a unique subjective state space. Econometrica, 69(4), pp.891934.

[124] Delavande, A., 2008. Measuring revisions to subjective expectations. Journal of Risk and Uncertainty, 36(1), pp.43-82.

[125] Delavande, Adeline, and Charles F. Manski. 2010. "Probabilistic Polling And Voting In The 2008 Presidential Election Evidence From The American Life Panel." Public Opinion Quarterly : nfq019.

[126] Delavande, Adeline, and Susann Rohwedder. 2008. "Eliciting Subjective Probabilities in Internet Surveys." Public Opinion Quarterly 72.5: 866891.

[127] Delavande, A. and Zafar, B., 2019. University choice: The role of expected earnings, nonpecuniary outcomes, and financial constraints. Journal of Political Economy, 127(5), pp.2343-2393.

[128] DeLiema, M., Deevy, M., Lusardi, A. and Mitchell, O.S., 2020. Financial fraud among older americans: Evidence and implications. The Journals of Gerontology: Series B, 75(4), pp.861-868.

[129] Deming, D.J., 2021. The Growing Importance of Decision-Making on the Job (No. w28733). National Bureau of Economic Research.

[130] Dixit, Avinash. 2002. "Paul Samuelson's Legacy." Annual Review of Economics Vol. 4: 1-31.

[131] Dominitz, Jeff, and Charles F. Manski. 1996. "Eliciting Student Expectations of the Returns to Schooling." Journal of Human Resources, 31, $1-26$.

[132] Dominitz, Jeff, and Charles F. Manski. 1997. "Using Expectations Data to Study Subjective Income Expectations." Journal of the American Statistical Association, 92, 855-867.

[133] Donaldson, M.S., Corrigan, J.M. and Kohn, L.T. eds., 2000. To err is human: building a safer health system.

[134] Donders, Franciscus Cornelius. 1868. "On the speed of mental processes." Translated by W. G. Koster, 1969. Acta Psychologica 30: 412-431.

[135] Dynan, Karen, Jonathan Skinner, and Stephen Zeldes. 2002. "The Importance of Bequests and life cycle Saving in Capital Accumulation: A New Answer." American Economic Review Papers and Proceedings, 274-278.

[136] Enke, B. and Graeber, T., 2019. Cognitive uncertainty (No. w26518). National Bureau of Economic Research. 
[137] Epper, T., Fehr, E., Fehr-Duda, H., Kreiner, C.T., Lassen, D.D., LethPetersen, S. and Rasmussen, G.N., 2020. Time discounting and wealth inequality. American Economic Review, 110(4), pp.1177-1205.

[138] Ericsson, K.A. and Simon, H.A., 1980. Verbal reports as data. Psychological review, $87(3)$, p.215.

[139] Falk, A., Neuber, T. and Strack, P., 2021. Limited Self-Knowledge and Survey Response Behavior.

[140] Farber, H.S., Hall, R. and Pencavel, J., 1993. The incidence and costs of job loss: 1982-91. Brookings papers on economic activity. Microeconomics, 1993(1), pp.73-132.

[141] Fehr, Ernst, and Antonio Rangel. 2011. "Neuroeconomic Foundations of Economic Choice - Recent Advances." Journal of Economic Perspectives, 25(4): 3-30.

[142] Feldman, N.E., Katuščák, P. and Kawano, L., 2016. Taxpayer confusion: Evidence from the child tax credit. American Economic Review, 106(3), pp.807-35.

[143] Finkelstein, A. and K. McGarry. 2006. "Multiple Dimensions of Private Information: Evidence from the Long-Term Care Insurance Market." American Economic Review, 96(4): 938-958.

[144] Fosgerau, M., Melo, E., De Palma, A. and Shum, M., 2020. Discrete choice and rational inattention: A general equivalence result. International Economic Review, 61(4), pp.1569-1589.

[145] Fudenberg, D., Strack, P. and Strzalecki, T., 2018. Speed, accuracy, and the optimal timing of choices. American Economic Review, 108(12), pp.3651-84.

[146] Fuster, Andreas, David Laibson, and Brock Mendel. 2010. "Natural expectations and macroeconomic fluctuations." Journal of Economic Perspectives 24 , no. 4: 67-84.

[147] Gabaix, X., 2014. A sparsity-based model of bounded rationality. The Quarterly Journal of Economics, 129(4), pp.1661-1710.

[148] Gabaix, X., Laibson, D., Moloche, G. and Weinberg, S., 2006. Costly information acquisition: Experimental analysis of a boundedly rational model. American Economic Review, 96(4), pp.1043-1068.

[149] Gandhi, T.K., Kachalia, A., Thomas, E.J., Puopolo, A.L., Yoon, C., Brennan, T.A. and Studdert, D.M., 2006. Missed and delayed diagnoses in the ambulatory setting: a study of closed malpractice claims. Annals of internal medicine, 145(7), pp.488-496. 
[150] Ganong, P. and Noel, P., 2019. Consumer spending during unemployment: Positive and normative implications. American economic review, 109(7), pp.2383-2424.

[151] Gathmann, C., Helm, I. and Schönberg, U., 2020. Spillover effects of mass layoffs. Journal of the European Economic Association, 18(1), pp.427-468.

[152] Gell-Mann, M. and Tsallis, C. eds., 2004. Nonextensive entropy: interdisciplinary applications. Oxford University Press.

[153] Geng, Sen. 2015. "Decision Time, Consideration Time, and Status Quo Bias." Economic Inquiry.

[154] Gillen, B., Snowberg, E. and Yariv, L., 2019. Experimenting with measurement error: Techniques with applications to the caltech cohort study. Journal of Political Economy, 127(4), pp.1826-1863.

[155] Glaeser, Edward L., and Charles G. Nathanson. 2015. "An Extrapolative Model of House Price Dynamics.” NBER Working Paper No. 21037.

[156] Glimcher, P., 2014, January. Understanding the hows and whys of decision-making: from expected utility to divisive normalization. In Cold Spring Harbor symposia on quantitative biology (Vol. 79, pp. 169-176). Cold Spring Harbor Laboratory Press.

[157] Gourinchas, P.O. and Parker, J.A., 2002. Consumption over the life cycle. Econometrica, 70(1), pp.47-89.

[158] Greenwood, Robin, and Andrei Shleifer. 2014. "Expectations of returns and expected returns." Review of Financial Studies 27, no. 3: 714-746.

[159] Gregory, V., 2020. Firms as learning environments: Implications for earnings dynamics and job search. Federal Reserve Bank of St. Louis, Research Division.

[160] Griffiths, T.L., Lieder, F. and Goodman, N.D., 2015. Rational use of cognitive resources: Levels of analysis between the computational and the algorithmic. Topics in cognitive science, $7(2)$, pp.217-229.

[161] Gul, F. and Pesendorfer, W., 2001. Temptation and self-control. Econometrica, 69(6), pp.1403-1435.

[162] Guo, C., Pleiss, G., Sun, Y. and Weinberger, K.Q., 2017, July. On calibration of modern neural networks. In International Conference on Machine Learning (pp. 1321-1330). PMLR.

[163] Guvenen, F., 2007. Learning your earning: Are labor income shocks really very persistent?. American Economic Review, 97(3), pp.687-712. 
[164] Guvenen, F., Karahan, F., Ozkan, S. and Song, J., 2015. What do data on millions of US workers reveal about life-cycle earnings risk? (No. w20913). National Bureau of Economic Research.

[165] Guvenen, F., G. Kaplan, J.Song, and J. Weidner. 2021. Lifetime Earnings in the United States over Six Decades

[166] Haaland, I., Roth, C. and Wohlfart, J., 2021. Designing Information Provision Experiments. Forthcoming, Journal of Economic Literature.

[167] Haavelmo, T., 1944. The probability approach in econometrics. Econometrica: Journal of the Econometric Society, pp.iii-115.

[168] Haavelmo, Trygve. 1958. "The role of the econometrician in the advancement of economic theory." Econometrica 351-357.

[169] Hainmueller, Jens, Dominik Hangartner, and Teppei Yamamoto. 2015. "Validating vignette and conjoint survey experiments against real-world behavior." Proceedings of the National Academy of Sciences 112, no. 8 (2015): 2395-2400.

[170] Haltiwanger, J.C., Hyatt, H.R., Kahn, L.B. and McEntarfer, E., 2018. Cyclical job ladders by firm size and firm wage. American Economic Journal: Macroeconomics, 10(2), pp.52-85.

[171] Handel, B.R. and Kolstad, J.T., 2015. Health insurance for" humans": Information frictions, plan choice, and consumer welfare. American Economic Review, 105(8), pp.2449-2500.

[172] Hanna, R., Mullainathan, S. and Schwartzstein, J., 2014. Learning through noticing: Theory and evidence from a field experiment. The Quarterly Journal of Economics, 129(3), pp.1311-1353.

[173] Hastings, J.S. and Weinstein, J.M., 2008. Information, school choice, and academic achievement: Evidence from two experiments. The Quarterly journal of economics, 123(4), pp.1373-1414.

[174] Hayek, Friedrich A. 1937. "Economics and knowledge." Economica: 33-54.

[175] Hayek, Friedrich A. 1945. "The Use of Knowledge in Society." American Economic Review 35, no. 4: 519-53

[176] Heathcote, J., Storesletten, K. and Violante, G.L., 2009. Quantitative macroeconomics with heterogeneous households. Annu. Rev. Econ., 1(1), pp.319-354.

[177] Hébert, B.M. and Jennifer, La'O, 2020. Information Acquisition, Efficiency, and Non-Fundamental Volatility (No. w26771). National Bureau of Economic Research. 
[178] Hébert, B.M. and Woodford, M., 2019. Rational inattention when decisions take time (No. w26415). National Bureau of Economic Research.

[179] Hébert, B.M. and Woodford, M., 2020. Neighborhood-based information costs (No. w26743). National Bureau of Economic Research.

[180] Heckman, J.J. and Rubinstein, Y., 2001. The importance of noncognitive skills: Lessons from the GED testing program. American Economic Review, 91(2), pp.145-149.

[181] Heckman, James J., and Sergio Urzua. 2010. "Comparing IV with structural models: What simple IV can and cannot identify." Journal of Econometrics 156.1: 27-37.

[182] Heckman, J.J. and Vytlacil, E., 2001. Policy-relevant treatment effects. American Economic Review, 91(2), pp.107-111.

[183] Heckman, J.J. and Vytlacil, E.J., 2007a. Econometric evaluation of social programs, part I: Causal models, structural models and econometric policy evaluation. Handbook of econometrics, 6, pp.4779-4874.

[184] Heckman, J.J. and Vytlacil, E.J., 2007b. Econometric evaluation of social programs, part II: Using the marginal treatment effect to organize alternative econometric estimators to evaluate social programs, and to forecast their effects in new environments. Handbook of econometrics, 6 , pp.4875-5143.

[185] Hendren, N., 2017. Knowledge of future job loss and implications for unemployment insurance. American Economic Review, 107(7), pp.17781823.

[186] Holt, C.A. and Laury, S.K., 2002. Risk aversion and incentive effects. American economic review, 92(5), pp.1644-1655.

[187] Hofman, J.M., Watts, D.J., Athey, S., Garip, F., Griffiths, T.L., Kleinberg, J., Margetts, H., Mullainathan, S., Salganik, M.J., Vazire, S. and Vespignani, A., 2021. Integrating explanation and prediction in computational social science. Nature, pp.1-8.

[188] Hoxby, C.M. and Turner, S., 2015. What high-achieving low-income students know about college. American Economic Review, 105(5), pp.514-17.

[189] Hurd, Michael D. 2009. "Subjective Probabilities in Household Surveys." Annual Review of Economics , 1: 543-562.

[190] Hurd, Michael D., and Kathleen McGarry. 2002. "The predictive validity of subjective probabilities of survival." Economic Journal 112.482: 966985. 
[191] Hurd, M.D. and McGarry, K., 1995. Evaluation of the subjective probabilities of survival in the health and retirement study. Journal of Human resources, pp.S268-S292.

[192] Hurd, M.D., Martorell, P., Delavande, A., Mullen, K.J. and Langa, K.M., 2013. Monetary costs of dementia in the United States. New England Journal of Medicine, 368(14), pp.1326-1334.

[193] Hurd, Michael and Susann Rohwedder. 2012. "Stock Price Expectations and Stock Trading." NBER Working Paper 17973.

[194] Jacobson, L.S., LaLonde, R.J. and Sullivan, D.G., 1993. Earnings losses of displaced workers. The American economic review, pp.685-709.

[195] Jacobson, L., LaLonde, R. and Sullivan, D.G., 2005. Estimating the returns to community college schooling for displaced workers. Journal of Econometrics, 125(1-2), pp.271-304.

[196] Johnson, Eric J., Colin Camerer, Sankar Sen, and Talia Rymon. 2002. "Detecting Failures of Backward Induction: Monitoring Information Search in Sequential Bargaining." Journal of Economic Theory 104, 1647.

[197] Joo, J., 2020. Rational inattention as an empirical framework: Application to the welfare effects of new-product introduction. Available at SSRN 3182795 .

[198] Jovanovic, B. and Nyarko, Y., 1994. The Bayesian foundations of learning by doing. National Bureau of Economic Research.

[199] Jones, C.I. and Tonetti, C., 2020. Nonrivalry and the Economics of Data. American Economic Review, 110(9), pp.2819-58.

[200] Juster, F. Thomas. 1966. "Consumer Buying Intentions and Purchase Probability: An Experiment in Survey Design." Journal of the American Statistical Association 61.315: 658-696.

[201] Kahneman, Daniel, and Patrick Egan. 2011. Thinking, fast and slow. Vol. 1. New York: Farrar, Straus and Giroux.

[202] Kahneman, Daniel. 1973. Attention and Effort. Vol. 1063. Englewood Cliffs, NJ: Prentice-Hall, 1973.

[203] Kahneman, D., Wakker, P.P. and Sarin, R., 1997. Back to Bentham? Explorations of experienced utility. The quarterly journal of economics, $112(2)$, pp.375-406.

[204] Kamenica, E. and Gentzkow, M., 2011. Bayesian persuasion. American Economic Review, 101(6), pp.2590-2615. 
[205] Kang, M.J. and Camerer, C., 2018. Measured anxiety affects choices in experimental "clock" games. Research in Economics, 72(1), pp.49-64.

[206] Katona, George. 1960. The powerful consumer. The powerful consumer.

[207] Kaur, S., Mullainathan, S., Oh, S. and Schilbach, F., 2021. Do Financial Concerns Make Workers Less Productive? (No. w28338). National Bureau of Economic Research.

[208] Kesternich, Iris, Florian Heiss, Daniel McFadden, and Joachim Winter. 2012. "Suit the Action to the Word, the Word to the Action: Hypothetical Choices and Real Decisions in Medicare Part D." Munich Discussion Paper, No. 2012-25

[209] Kézdi, Gabor and Robert J. Willis. 2011. "Household Stock Market Beliefs and Learning." NBER Working Paper 17614.

[210] Khaw, M.W., Li, Z. and Woodford, M., 2017. Risk aversion as a perceptual bias (No. w23294). National Bureau of Economic Research.

[211] Khaw, M.W., Stevens, L. and Woodford, M., 2017. Discrete adjustment to a changing environment: Experimental evidence. Journal of Monetary Economics, 91, pp.88-103.

[212] Kimball, Miles S., Claudia R. Sahm, and Matthew D. Shapiro. 2008. "Imputing risk tolerance from survey responses." Journal of the American Statistical Association 103.483: 1028-1038.

[213] Kleinberg, J., Lakkaraju, H., Leskovec, J., Ludwig, J. and Mullainathan, S., 2018. Human decisions and machine predictions. The quarterly journal of economics, 133(1), pp.237-293.

[214] Kling, J.R., Mullainathan, S., Shafir, E., Vermeulen, L.C. and Wrobel, M.V., 2012. Comparison friction: Experimental evidence from Medicare drug plans. The quarterly journal of economics, 127(1), pp.199-235.

[215] Kocher, Martin G., and Matthias Sutter. 2006. "Time is Money-Time Pressure, Incentives, and the Quality of Decision-making." Journal of Economic Behavior and Organization, 61: 375-39.

[216] Kool, W. and Botvinick, M., 2018. Mental labour. Nature human behaviour, 2(12), pp.899-908.

[217] Koopmans, T.C., 1962. On flexibility of future preference (No. 150). Cowles Foundation for Research in Economics, Yale University.

[218] Koopmans, T.C. and Beckmann, M., 1957. Assignment problems and the location of economic activities. Econometrica: journal of the Econometric Society, pp.53-76. 
[219] Koopmans, Tjalling C. 1949. "Identification problems in economic model construction." Econometrica: 125-144.

[220] Kopczuk, Wojciech, and Joseph P. Lupton. 2007. "To leave or not to leave: The distribution of bequest motives." Review of Economic Studies 74, no. 1: $207-235$.

[221] Kopecky, Karen A., and Tatyana Koreshkova. 2014. "The impact of medical and nursing home expenses on savings." American Economic Journal: Macroeconomics 6, no. 3: 29-72.

[222] Köszegi, B. and Rabin, M., 2008. Choices, situations, and happiness. Journal of Public Economics, 92(8-9), pp.1821-1832.

[223] Kotlikoff, Laurence J., and Lawrence H. Summers. 1981. "The role of intergenerational transfers in aggregate capital accumulation." Journal of Political Economy 89, no. 4: 706-732.

[224] Krajbich, Ian, Dingchao Lu, Colin Camerer, and Antonio Rangel. 2012. "The Attentional Drift-diffusion Model Extends to Simple Purchasing Decisions." Frontiers in Psychology, 3: 193.

[225] Krajbich, Ian, and Antonio Rangel. 2011. "Multialternative drift-diffusion model predicts the relationship between visual fixations and choice in value-based decisions." Proceedings of the National Academy of Sciences 108.33: 13852-13857.

[226] Kreiner, Claus Thustrup, David Dreyer Lassen, and Søren Leth-Petersen. 2014. "Measuring the accuracy of survey responses using administrative register data: evidence from Denmark." In Improving the measurement of consumer expenditures, pp. 289-307. University of Chicago Press. Annuity Puzzle." Review of Economic Dynamics, Vol. 15, Pages 226-243.32.

[227] Kreps, David M. "A Representation Theorem for "Preference for Flexibility"." Econometrica 47, no. 3 (1979): 565-77. Accessed August 9, 2021. doi:10.2307/1910406.

[228] Kreps, D., and Porteus, E. (1978). Temporal Resolution of Uncertainty and Dynamic Choice Theory. ¡i ¿Econometrica,i/i $i_{i} i{ }_{i} 46 i / i_{i}(1), 185-200$. doi:10.2307/1913656Zara

[229] Krueger, A.B. and Mueller, A.I., 2012. Time use, emotional well-being, and unemployment: Evidence from longitudinal data. American Economic Review, 102(3), pp.594-99.

[230] Kuchler, T. and Zafar, B., 2019. Personal experiences and expectations about aggregate outcomes. The Journal of Finance, 74(5), pp.2491-2542.

[231] Langa, K.M. and Cutler, D., 2015. Opportunities for new insights on the life-course risks and outcomes of cognitive decline in the Kavli HUMAN Project. Big data, 3(3), pp.189-192. 
[232] Langa, Kennet, Eric B. Larson, Eileen M. Crimmins, Jessica D. Faul, Deborah A. Levine, Mohammed U. Kabeto and David R. Weir. 2017. A Comparisosn of the Prevalence of Dementia in the United State in 2000 and 2012. JAMA International Medicine, vol. 177, 51-58.

[233] Lieder, F. and Griffiths, T.L., 2020. Resource-rational analysis: Understanding human cognition as the optimal use of limited computational resources. Behavioral and Brain Sciences, 43.

[234] Lindqvist, E., Östling, R. and Cesarini, D., 2020. Long-run effects of lottery wealth on psychological well-being. The Review of Economic Studies, 87(6), pp.2703-2726.

[235] Lise, J., Meghir, C. and Robin, J.M., 2016. Matching, sorting and wages. Review of Economic Dynamics, 19, pp.63-87.

[236] Lockwood, L.M., 2012. Bequest motives and the annuity puzzle. Review of economic dynamics, 15(2), pp.226-243.

[237] Low, H., Meghir, C. and Pistaferri, L., 2010. Wage risk and employment risk over the life cycle. American Economic Review, 100(4), pp.1432-67.

[238] Louie, K., Khaw, M.W. and Glimcher, P.W., 2013. Normalization is a general neural mechanism for context-dependent decision making. Proceedings of the National Academy of Sciences, 110(15), pp.6139-6144.

[239] Love, David A., Michael G. Palumbo, and Paul A. Smith. 2009. "The trajectory of wealth in retirement." Journal of Public Economics 93, no. 1-2: 191-208.

[240] Low, H., Meghir, C. and Pistaferri, L., 2010. Wage risk and employment risk over the life cycle. American Economic Review, 100(4), pp.1432-67.

[241] Luce, R. Duncan. 1956. "Semiorders and a Theory of Utility Discrimination." Econometrica: 178-191.

[242] Luce, R. Duncan. 1958. "A probabilistic theory of utility." Econometrica: 193-224.

[243] Luce, R. Duncan. 1986. Response Times: Their Role in Inferring Elementary Mental Organization. New York: Oxford University Press

[244] Luce, R.D. and Tukey, J.W., 1964. Simultaneous conjoint measurement: A new type of fundamental measurement. Journal of mathematical psychology, 1(1), pp.1-27.

[245] Ma, W.J. and Woodford, M., 2020. Multiple conceptions of resource rationality. Behavioral and Brain Sciences, 43.

[246] Machlup, F., 1993. Uses, value, and benefits of knowledge. Knowledge, 14(4), pp.448-466. 
[247] Mackowiak, B., Matejka, F. and Wiederholt, M., 2020. Rational inattention: A review. CEPR Discussion Papers, 15408.

[248] Maestas, N., 2010. Back to work expectations and realizations of work after retirement. Journal of Human Resources, 45(3), pp.718-748.

[249] Malmendier, Ulrike, and Stefan Nagel. 2011. "Depression babies: do macroeconomic experiences affect risk taking?" Quarterly Journal of Economics 126: 373-416.

[250] Malmendier, Ulrike, and Stefan Nagel. 2015. "Learning from inflation experiences." Quarterly Journal of Economics 131, no. 1: 53-87.

[251] Malmendier, U. and Shen, L.S., 2018. Scarred consumption (No. w24696). National Bureau of Economic Research.

[252] Malone, Trey and Jayson L. Lusk. 2018. "Consequences of Participant Inattention with an Application to Carbon Taxes for Meat Products." Ecological Economics. 145: 218-230.

[253] Mani, A., Mullainathan, S., Shafir, E. and Zhao, J., 2013. Poverty impedes cognitive function. science, 341(6149), pp.976-980.

[254] Manski, Charles F. 1990. "The Use of Intentions Data to Predict Behavior: A Best-case Analysis." Journal of the American Statistical Association 85.412: 934-940.

[255] Manski, Charles F. 2004. "Measuring Expectations." Econometrica: 13291376.

[256] Manski, Charles F. 2018. "Survey measurement of probabilistic macroeconomic expectations: progress and promise." NBER Macroeconomics Annual 32, no. 1: 411-471.

[257] Manzini, Paola; Mariotti, Marco. 2014. "Stochastic choice and consideration sets." Econometrica, Vol. 89, No. 3, p. 1153-1176.

[258] Marschak, Jacob. 1953. Economic measurements for policy and prediction." In W. Hood, T. Koopmans (Eds.), Studies in Econometric Method, Wiley, New York, pp. 1-26.

[259] Martin, D. and Marx, P., 2021. A Robust Test of Prejudice for Discrimination Experiments.

[260] Martin, D. and Muñoz-Rodriguez, E., 2019. Misperceiving Mechanisms: Imperfect Perception and the Failure to Recognize Dominant Strategies. Available at SSRN 3316346.

[261] Masatlioglu, Y., Orhun, A.Y. and Raymond, C., 2017. Intrinsic information preferences and skewness. Ross School of Business Paper 
[262] Matějka, Filip, and Alisdair McKay. 2015. "Rational Inattention to Discrete Choices: a New. Foundation for the Multinomial Logit Model." American Economic Review , vol. 105 (1), p. 272-298.

[263] McFadden, Daniel. 1974. "Conditional Logit Analysis of Qualitative Choice Behavior." in P. Zarembka, ed, Frontiers of Econometrics, Academic Press: New York, 105-142.

[264] McFadden, Daniel. 1986. "The Choice Theory Approach to Market Research." Marketing Science, 5, 275-297.

[265] McGarry, Kathleen. 1999. "Inter vivos transfers and intended bequests." Journal of Public Economics 73, no. 3: 321-351.

[266] Meghir, C. and Pistaferri, L., 2011. Earnings, consumption and life cycle choices. In Handbook of labor economics (Vol. 4, pp. 773-854). Elsevier.

[267] Menzio, G., Telyukova, I.A. and Visschers, L., 2016. Directed search over the life cycle. Review of Economic Dynamics, 19, pp.38-62.

[268] Miao, J. and Xing, H., 2020. Dynamic Discrete Choice under Rational Inattention.

[269] Modigliani, Franco, and Richard Brumberg. 1954. "Utility analysis and the consumption function: An interpretation of cross-section data." Franco Modigliani 1: 388-436.

[270] Morikawa, Masayuki, 2021. "Work-from-Home Productivity during the COVID-19 Pandemic: Evidence from Surveys of Employees and Employers," SSPJ Discussion Paper Series DP20-007, Service Sector Productivity in Japan: Determinants and Policies, Institute of Economic Research, Hitotsubashi University

[271] Morris, S. and Strack, P., 2019. The wald problem and the relation of sequential sampling and ex-ante information costs. Available at SSRN 2991567.

[272] Morrison, W. and Taubinsky, D., 2019. Rules of thumb and attention elasticities: Evidence from under-and overreaction to taxes (No. w26180). National Bureau of Economic Research.

[273] Mueller, A.I., Spinnewijn, J. and Topa, G., 2021. Job Seekers' Perceptions and Employment Prospects: Heterogeneity, Duration Dependence, and Bias. American Economic Review, 111(1), pp.324-63.

[274] Musslick, S. and Cohen, J.D., 2021. Rationalizing constraints on the capacity for cognitive control. Trends in Cognitive Sciences.

[275] Musslick, S., Cohen, J.D. and Shenhav, A., 2018. Estimating the costs of cognitive control from task performance: theoretical validation and potential pitfalls. In CogSci. 
[276] Neter, John \& Joseph Waksberg. 1964. "A Study of Response Errors in Expenditures Data from Household Interviews." Journal of the American Statistical Association, 59:305, 18-55.

[277] Nicholas, L.H., Langa, K.M., Bynum, J.P. and Hsu, J.W., 2021. Financial presentation of Alzheimer disease and related dementias. JAMA internal medicine, 181(2), pp.220-227.

[278] Okonkwo, O.C., Wadley, V.G., Griffith, H.R., Belue, K., Lanza, S., Zamrini, E.Y., Harrell, L.E., Brockington, J.C., Clark, D., Raman, R. and Marson, D.C., 2008. Awareness of deficits in financial abilities in patients with mild cognitive impairment: going beyond self-informant discrepancy. The American Journal of Geriatric Psychiatry, 16(8), pp.650-659.

[279] Oppenheimer, D.M., Meyvis, T. and Davidenko, N., 2009. Instructional manipulation checks: Detecting satisficing to increase statistical power. Journal of experimental social psychology, 45(4), pp.867-872.

[280] Pattanayak, K. and Krishnamurthy, V., 2021. Unifying Classical and Bayesian Revealed Preference. arXiv preprint arXiv:2106.14486.

[281] Payne, J.W., Payne, J.W., Bettman, J.R. and Johnson, E.J., 1993. The adaptive decision maker. Cambridge university press.

[282] Phelps, E.S., 1972. The statistical theory of racism and sexism. The american economic review, 62(4), pp.659-661.

[283] Plassman, B.L., Langa, K.M., Fisher, G.G., Heeringa, S.G., Weir, D.R., Ofstedal, M.B., Burke, J.R., Hurd, M.D., Potter, G.G., Rodgers, W.L. and Steffens, D.C., 2007. Prevalence of dementia in the United States: the aging, demographics, and memory study. Neuroepidemiology, 29(1-2), pp.125-132.

[284] Plott, C.R. and Zeiler, K., 2005. The willingness to pay-willingness to accept gap, the" endowment effect," subject misconceptions, and experimental procedures for eliciting valuations. American Economic Review, 95(3), pp.530-545.

[285] Poterba, James M., Steven F. Venti, and David A. Wise. 2010. "The asset cost of poor health." No. w16389. National Bureau of Economic Research.

[286] Poterba, James, Steven Venti, and David Wise. 2011. "The composition and drawdown of wealth in retirement." Journal of Economic Perspectives 25, no. 4: 95-118.

[287] Poterba, James M., "Retirement Security in an Aging Population,American Economic Review: Papers and Proceedings, 2014, 104, $1-30$. 
[288] Rabin, M. and Thaler, R.H., 2001. Anomalies: risk aversion. Journal of Economic perspectives, 15(1), pp.219-232.

[289] Rambachan, Ashesh. Identifying Prediction Mistakes in Observational Data. 2021.

[290] Ratcliff, Roger. 1978. "A Theory of Memory Retrieval." Psychological Review, 85(2): 59 .

[291] Ratcliff, Roger, and Gail McKoon. 2008. "The Diffusion Decision Model: Theory and Data for Two-choice Decision Tasks." Neural Computation, 20: $873-922$.

[292] Rayo, L. and Becker, G.S., 2005. On the foundations of happiness. Mimeo, University of Chicago.

[293] Recalde, M.P., Riedl, A. and Vesterlund, L., 2017. Error prone inference from response time: The case of intuitive generosity.

[294] Reinecke, K. and Bernstein, A., 2013. Knowing what a user likes: A design science approach to interfaces that automatically adapt to culture. Mis Quarterly, pp.427-453.

[295] Reuben, E., Sapienza, P. and Zingales, L., 2014. How stereotypes impair women's careers in science. Proceedings of the National Academy of Sciences, 111(12), pp.4403-4408.

[296] Reutskaja, Elena, Johannes Pulst-Korenberg, Rosemarie Nagel, Colin Camerer, and Antonio Rangel. 2011. "Economic Decision-making under Conditions of Extreme Time Pressure and Option Overload: an Eyetracking Study." American Economic Review, 900-926.

[297] Rohwedder, S. and Willis, R.J., 2010. Mental retirement. Journal of Economic Perspectives, 24(1), pp.119-38.

[298] Roth, A.E. and Sotomayor, M., 1992. Two-sided matching. Handbook of game theory with economic applications, 1, pp.485-541.

[299] Roth, C. and Wohlfart, J., 2020. How do expectations about the macroeconomy affect personal expectations and behavior?. Review of Economics and Statistics, 102(4), pp.731-748.

[300] Rozsypal, F. and Schlafmann, K., 2017. Overpersistence bias in individual income expectations and its aggregate implications.

[301] Rubinstein, Ariel. 2007. "Instinctive and Cognitive Reasoning: A Study of Response Times." Economic Journal, 117: 1243-1259.

[302] Ruhm, C.J., 1991. Are workers permanently scarred by job displacements?. The American economic review, 81(1), pp.319-324. 
[303] Rupert, P. and Zanella, G., 2015. Revisiting wage, earnings, and hours profiles. Journal of Monetary Economics, 72, pp.114-130.

[304] Samuelson, Paul A. 1938. "A Note on the Pure Theory of Consumer's Choice." Economica, 5:61-71.

[305] Savage, L.J., 1954. The foundations of statistics. Courier Corporation.

[306] Savage, L.J., 1971. Elicitation of personal probabilities and expectations. Journal of the American Statistical Association, 66(336), pp.783-801.

[307] Schotter, Andrew, and Isabel Trevino. 2013. "Is Response Time Predictive of Choice? An Experimental Study of Threshold Strategies." Mimeo.

[308] Seim, D., 2019. On the incidence and effects of job displacement: Evidence from Sweden. Labour Economics, 57, pp.131-145.

[309] Shavell, S., 1995. The appeals process as a means of error correction. The Journal of Legal Studies, 24(2), pp.379-426.

[310] Shaw, Marilyn L., and Peter Shaw. 1977. "Optimal Allocation of Cognitive Resources to Spatial Locations." Journal of Experimental Psychology: Human Perception and Performance 3, no. 2: 201.

[311] Sibson, R., 1969. Information radius. Zeitschrift für Wahrscheinlichkeitstheorie und verwandte Gebiete, 14(2), pp.149-160.

[312] Sims, Christopher A. 1998. "Stickiness." Carnegie-Rochester Conference Series on Public Policy 49, 317-356.

[313] Sims, Christopher A. 2003. "Implications of Rational Inattention." Journal of Monetary Economics 50, 665-690.

[314] Smith, Karen, Mauricio Soto, and Rudolph G. Penner. 2009. "How seniors change their asset holdings during retirement. "The Retirement Policy Program: Discussion Paper: 09-06.

[315] Spiliopoulos, Leonidas, and Andreas Ortmann. 2014. "The BCD of Response Time Analysis in Experimental Economics." Available at http://papers.ssrn.com/sol3/papers.cfm?abstract_id=2401325.

[316] Stantcheva, S., 2020. Understanding tax policy: How do people reason? (No. w27699). National Bureau of Economic Research.

[317] Stephenson, M.C., 2010. Information acquisition and institutional design. Harv. L. Rev., 124, p.1422.

[318] Stigler, George J. 1961. "The Economics of Information." Journal of Political Economy: 213-225. 
[319] Taubinsky, D. and Rees-Jones, A., 2018. Attention variation and welfare: theory and evidence from a tax salience experiment. The Review of Economic Studies, 85(4), pp.2462-2496.

[320] Tellenbach, B., Burkhart, M., Sornette, D. and Maillart, T., 2009, April. Beyond shannon: Characterizing internet traffic with generalized entropy metrics. In International conference on passive and active network measurement (pp. 239-248). Springer, Berlin, Heidelberg.

[321] Thurstone, Louis Leon. 1927. "A Law of Comparative Judgement." Psychological Review, 34, 273-286.

[322] Thurstone, Louis Leon. 1931. "The indifference function." Journal of Social Psychology, 2, 139-167.

[323] Topel, R., 1990, September. Specific capital and unemployment: Measuring the costs and consequences of job loss. In Carnegie-Rochester conference series on public policy (Vol. 33, pp. 181-214). North-Holland.

[324] Topel, R.H. and Ward, M.P., 1992. Job mobility and the careers of young men. The Quarterly Journal of Economics, 107(2), pp.439-479.

[325] Toussaert, S., 2018. Eliciting Temptation and Self-Control Through Menu Choices: A Lab Experiment. Econometrica, 86(3), pp.859-889.

[326] Van der Klaauw, Wilbert. 2012. "On the use of expectations data in estimating structural dynamic choice models." Journal of Labor Economics, 30(3), 521-554.

[327] Veldkamp, L., 2020. The Research Agenda: Laura Veldkamp on Modeling and Measuring the Data Economy. EconomicDynamics Newsletter, 21(1).

[328] Von Neumann, J. and Morgenstern, O., 1944. Theory of games and economic behavior. Princeton university press.

[329] Von Wachter, T., Handwerker, E.W. and Hildreth, A.K., 2009. Estimating the'True'Cost of Job Loss: Evidence Using Matched Data from California 1991-2000. US Census Bureau Center for Economic Studies Paper No. CES-WP-09-14.

[330] Wachter, J.A. and Kahana, M.J., 2019. A retrieved-context theory of financial decisions (No. w26200). National Bureau of Economic Research.

[331] Weber, E. H. 1834. On the Tactile Senses. H.E. Ross and D.J.Murray Trans. and Ed. New York: Experimental Psychology Series.

[332] Weidmann, B. and Deming, D.J., 2020. Team players: how social skills improve group performance (No. w27071). National Bureau of Economic Research. 
[333] Wilcox, Nathaniel T. 1993. "Lottery Choice: Incentives, Complexity and Decision Time." Economic Journal: 1397-1417.

[334] Wiswall, Matthew, and Basit Zafar. 2015a. "Determinants of College Major Choice: Identification using an Information Experiment." Review of Economic Studies, 82.2: 791-824.

[335] Wiswall, Matthew, and Basit Zafar. 2015b. "How Do College Students Respond to Public Information about Earnings?" Journal of Human Capital 9.2: $117-169$.

[336] Wiswall, M. and Zafar, B., 2018. Preference for the workplace, investment in human capital, and gender. The Quarterly Journal of Economics, 133(1), pp.457-507.

[337] Wiswall, M. and Zafar, B., 2021. Human capital investments and expectations about career and family. Journal of Political Economy, 129(5), pp.1361-1424.

[338] Woodford, M., 2020. Modeling imprecision in perception, valuation, and choice. Annual Review of Economics, 12, pp.579-601.

[339] Woodford, Michael. 2012. "Inattentive Valuation and Reference Dependent Choice." Columbia University Working Paper 